\title{
Migrating meter-scale bedforms on Martian dark dunes: Are terrestrial aeolian ripples good analogues?
}

\author{
David A. Vaz ${ }^{\mathrm{a}, \mathrm{b}, *}$, S. Silvestro ${ }^{\mathrm{c}, \mathrm{d}}$, Pedro T.K. Sarmento ${ }^{\mathrm{a}}$, M. Cardinale ${ }^{\mathrm{e}}$

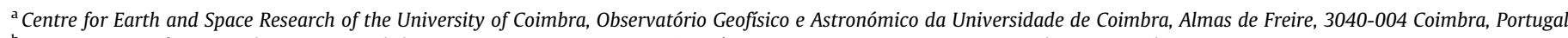 \\ ${ }^{\mathrm{b}}$ CERENA-Centre for Natural Resources and the Environment, Instituto Superior Técnico, Av. Rovisco Pais, 1049-001 Lisboa, Portugal \\ ${ }^{\mathrm{C}}$ INAF - Osservatorio Astronomico di Capodimonte, Napoli, Italy \\ ${ }^{\mathrm{d}}$ SETI Institute, Carl Sagan Center, 189 Bernardo Ave Suite 100, Mountain View, CA, USA \\ e DiSPUTER, Università Degli Studi G. d'Annunzio, Chieti, Italy
}

\section{A R T I C L E I N F O}

\section{Article history:}

Received 17 March 2016

Revised 8 August 2016

Accepted 8 August 2016

Available online 16 August 2016

\section{Keywords:}

Ripples

Dune patterns

Bedforms

Mars

\begin{abstract}
A B S T R A C T
Using automatic bedform mapping, principal component analysis and clustering we present a multiscale morphodynamic survey of dunes and meter-scale ripples on Herschel crater, Mars. The main purpose of this study is to assess if the morphology and temporal evolution of Martian meter-scale ripples is comparable to the morphodynamic characteristics of terrestrial aeolian impact ripples.

We demonstrate that the spatial variations of the mapped dune patterns are correlated with substrate topography, which also influences the spatial distribution of the height and celerity of dunes' slipfaces. This topographic forcing is also patent on the spatial distribution of the ripples, thus proving that a multiscale coupling of active bedforms exists on Herschel under the present surface conditions.

We found that Martian meter-scale ripples are morphologically distinct from terrestrial aeolian ripples, presenting a lower degree of straightness. Only $\sim 3 \%$ of the mapped ripples can be considered sinuous or straight bedforms. Moreover, we conclude that this two-dimensional sub-population is restricted to well define dune settings, where factors that promote the elongation of the meter-scale ripples were identified: gravity transport on higher slopes, bedform obliquity and flow convergence on the leeward side of dunes. We also report that the different sets of ripples that were mapped and segmented do not present a transverse migration. Therefore we conclude that terrestrial aeolian ripples are not good analogues for Martian meter-scale bedforms, either in terms of morphology or dynamic evolution.
\end{abstract}

(c) 2016 Elsevier B.V. All rights reserved.

\section{Introduction}

Aeolian ripples are the smallest bedforms formed by the action of winds over unconsolidated sediments. They generally form perpendicularly to the wind flow and migrate downwind, characteristics which enable their use to infer wind conditions on planetary surfaces (e.g., Bridges et al., 2013). On Earth, aeolian impact ripples consist in long and straight undulations with typical spacing between crests of $\sim 10 \mathrm{~cm}$ and presenting asymmetric profiles (Bagnold, 1941; Sharp, 1963). Ripple morphology is mainly influenced by granulometry and wind speed, resulting from the saltation and induced creep of the sediments (Bagnold, 1941; Andreotti et al., 2006; Pelletier, 2009).

Covering Martian dark dunes, bedforms with spacing ranging between 1 and $5 \mathrm{~m}$ and migrating under present day wind regime

\footnotetext{
* Corresponding author at: CITEUC - Observatório Geofísico e Astronómico da Universidade de Coimbra, Almas de Freire, 3040-004 Coimbra, Portugal.

E-mail address: davidvaz@uc.pt (D.A. Vaz).
}

up to $5 \mathrm{~m}$ per Earth year (Silvestro et al., 2010, 2011) have been interpreted, described and named as ripples. These large ripples were used to reconstruct Martian wind regimes and to derive sand fluxes (Bridges et al., 2012; Geissler et al., 2013; Silvestro et al., 2013), providing insights on the seasonal variability of aeolian transport processes on Mars (Ayoub et al., 2014). The patterns they form are not uniform at a dune field scale, being clearly influenced by complex dune topography and slopes (Ewing et al., 2010; Jackson et al., 2015; Zimbelman and Johnson, 2015). This diversity of patterns is an important aspect when mapping short-term local wind flows (Vaz and Silvestro, 2014; Liu and Zimbelman, 2015), although a systematic study of the different patterns has not been performed.

The classification of these Martian meter-scale bedforms as aeolian ripples was essentially based on morphodynamic characteristics: 1 ) they are regularly spaced linear bedforms; 2) covering all sorts of dune types; 3 ) and actively migrating. All these evidences were derived from the analysis of time sequences of HiRISE 

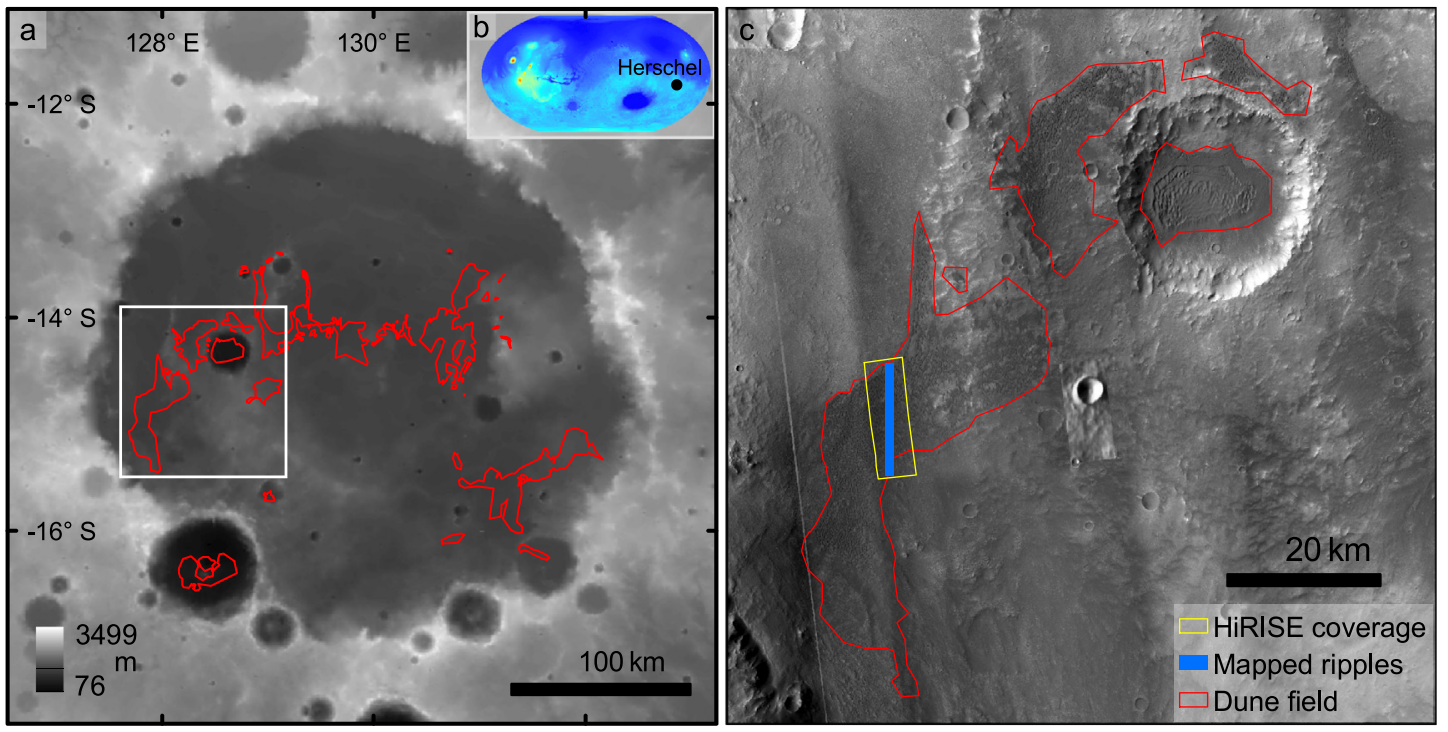

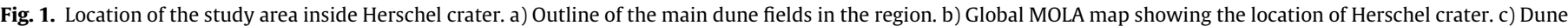
fields analyzed in this work, the HiRISE coverage and the area where ripple patterns were mapped are shown.

(High Resolution Imaging Science Experiment) images (with a best attainable spatial resolution of $\sim 0.25 \mathrm{~m} /$ pixel, McEwen et al., 2007), thus ignoring among other things the possible existence of finer-scale bedforms, the true tri-dimensional morphology of the bedforms and most importantly the physical processes (the relative contribution of saltation, reptation, suspension or avalanching) responsible for their formation and evolution. Therefore, the parallelism between terrestrial aeolian ripples and these Martian meterscale bedforms, namely their transverse nature and formation by saltation related processes, are still assumptions and not proven facts (Silvestro et al., 2015b; Vaz et al., 2015b). In effect, during the review process of this work Lapotre et al. (2016a) recently challenged some of these assumptions, also discussing the distinctive nature of the Martian meter-scale bedforms and suggesting that they resemble fluid-drag ripples. As it will be shown throughout this paper, both works independently support the notion that the Martian bedforms are different from terrestrial aeolian ripples. Even so, for simplicity we will continue to refer to these meterscale bedforms as ripples. However, we do not intend to imply any a priori formation mechanism or morphodynamic behavior by using this term.

Here we present a detailed multiscale analysis of dune morphodynamics and ripple patterns on a dune field located in Herschel crater (Fig. 1). Aeolian activity in this region was previously characterized by Cardinale et al. (2016). Under the influence of winds coming from north, a migration rate of 0.21 and $0.3 \mathrm{~m} /$ Earth year was measured for the dunes and ripples respectively. The herein analysis complements the latter by focusing on the spatial distribution of bedform patterns. By integrating ripple pattern properties, dune morphometric parameters, migration measurements, and a wind model, we identify distinct sets of bedforms which directly challenge the often drawn parallel between terrestrial aeolian ripples and Martian meter-scale ripples. Finally, we discuss some of the first observations made by the Curiosity rover at the Bagnold Dunes of Gale crater to support our orbital analysis.

\section{Data and methods}

We present an integrated multiscale analysis of aeolian morphologies using automatic and semi-automatic mapping procedures. These methods were previously introduced and validated
(Vaz and Silvestro, 2014; Vaz et al., 2015a) and are in this study used to: 1) map the dune patterns at a regional scale using a CTX (Mars Reconnaissance Orbiter Context Camera) mosaic; 2) map and characterize the morphology and migration rates of slipfaces using a HiRISE digital terrain model (DTM) and stereo images; 3 ) map meter-scale ripples and integrate the mapped patterns with the migration displacement fields and a simplified topographic wind effect model. The final stage of the data analysis consists in the clustering of the mapped features at two different scales. A regional clustering of the mapped dune morphologies is used to investigate the spatial variations of the dune patterns while the clustering of the meter-scale ripples is made to access the relations between pattern characteristics, wind and dune morphometric settings.

\subsection{Regional aeolian setting characterization}

To provide the necessary context for the detailed ripple analysis, we have mapped the region's dune morphologies applying the Object-based Dune Analysis (OBDA) technique described in (Vaz et al., 2015a). For this purpose, a geometrically controlled CTX mosaic with a spatial resolution of $7 \mathrm{~m} /$ pixel was created using ISIS (Integrated Software for Imagers and Spectrometers). The accuracy of the supervised object classification which enables the segmentation of the bedrock features, slipfaces or other dune elements was $93.5 \%$ (Fig. 2). Similar accuracies were obtained for other dune fields on Mars (Vaz et al., 2015a), even so data quality was further improved by manually editing the classification.

A regular grid with a spacing of $2 \mathrm{~km}$ is used to integrate several pattern characteristics, including directional and morphometric parameters computed from the Mars Orbiter Laser Altimeter (MOLA) DTM. This is the same type of output described in Vaz et al. (2015a), and is used in this work as input to a principal component analysis (PCA) and clustering algorithm (see Section 2.4.1). To apply these techniques we computed for each grid node: the length-weighted mean vector magnitude $\left(\bar{R}_{L}\right)$; the circular standard deviation (CSTD); several parameters that characterize the trend of the mapped structures, namely the azimuth and frequency of the primary kernel modes ( $k_{\text {mode } 1}$ and $\left.k_{\text {freq } 1}\right)$ and the modal ratio $\left(k_{\text {mrat }}\right)$ which measures the degree of bimodality of the trends (Vaz et al., 2015a); the mean, standard deviation and median lengths of 

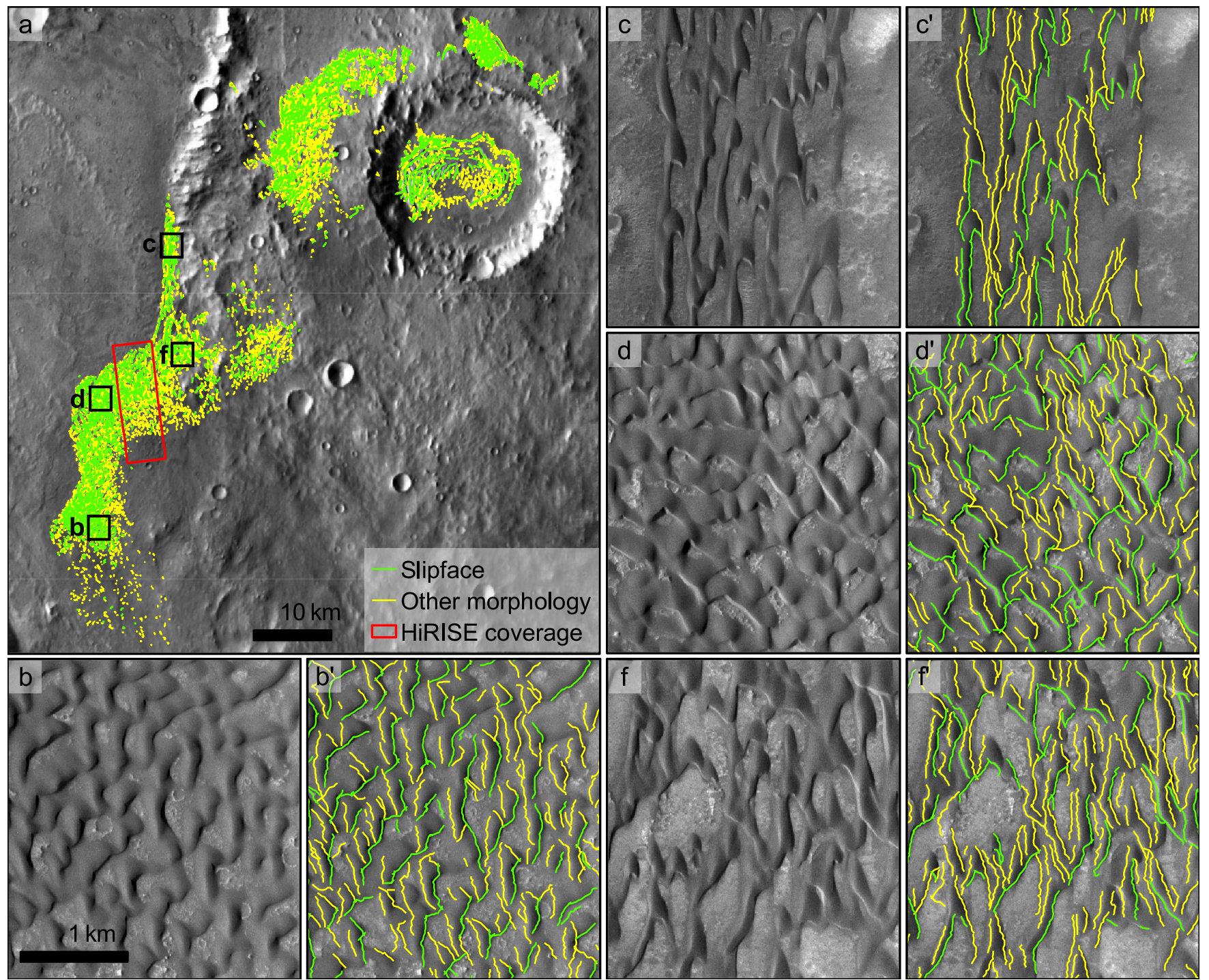

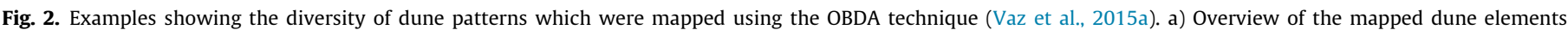

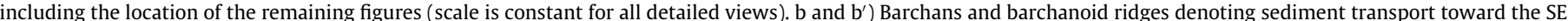

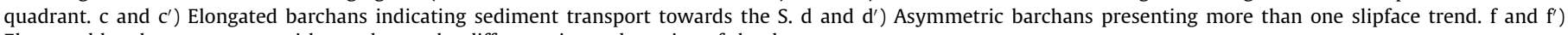
Elongated barchans, compare with $\mathrm{c}$ and note the different size and spacing of the dunes.

the mapped features ( $\bar{L}, s_{L}$ and $\operatorname{med}_{L}$ respectively); and the total number of aeolian features as well as the number of features classified as slipfaces ( $n_{\text {all }}$ and $\left.n_{\text {slipfaces }}\right)$.

\subsection{Dune morphodynamics}

The HiRISE data discussed in this paper is the same used by Cardinale et al. (2016). It includes a DTM and two orthorectified images, the PSP_002860_1650 acquired in 7/3/2007 (this will be referred as T0) and the ESP_020384_1650 acquired in 1/12/2012 (T1 image).

The HiRISE images and DTM are also used to map and study dune morphologies. Following the technique of Vaz (2011) and Vaz et al. (2014), we used a non-parametric multiscale morphological gradient (Fig. 3c) to map all the scarps from the DTM, while a supervised object-based classification process (Vaz et al., 2014) allows the segmentation of the slipface traces (Fig. 3d). This procedure generates continuous height measurements along the slipface traces, while the aspect angle (the direction of steepest descent) derived from the DTM is used to provide the direction of slipface advance (Fig. 3e).
To complement this characterization, we have also used the slipface migration data obtained by manual mapping of the lee fronts (Cardinale et al., 2016). Slipfaces covered by ripples indicating longitudinal sediment transport were not mapped. Assuming a bi-orthogonal migration of the lee front lines (Fig. 4a) we have computed the migration rates between times T0 and T1 (Fig. 4b and c). In order to highlight slipface morphodynamic spatial variations, we subsampled the height-weighted and migration vector fields at a $500 \mathrm{~m}$ resolution.

\subsection{Ripple mapping and characterization}

Ripples were mapped automatically (Vaz and Silvestro, 2014) for a N-S section of the dune field (Fig. 1c) using both T0 and T1 images, producing a mask outlining the rippled sand patches and dunes, and a series of lines representing the meter-scale ripples (Fig. 5a and b). The directional statistics (Fig. 5c), length and wavelength (Fig. 5f) of the large ripples are locally computed from the mapped lines and merged on a grid with $10 \mathrm{~m}$ spacing between nodes. The DTM is used to provide morphometric parameters (elevation, aspect and slope angle) which are locally sampled for each 

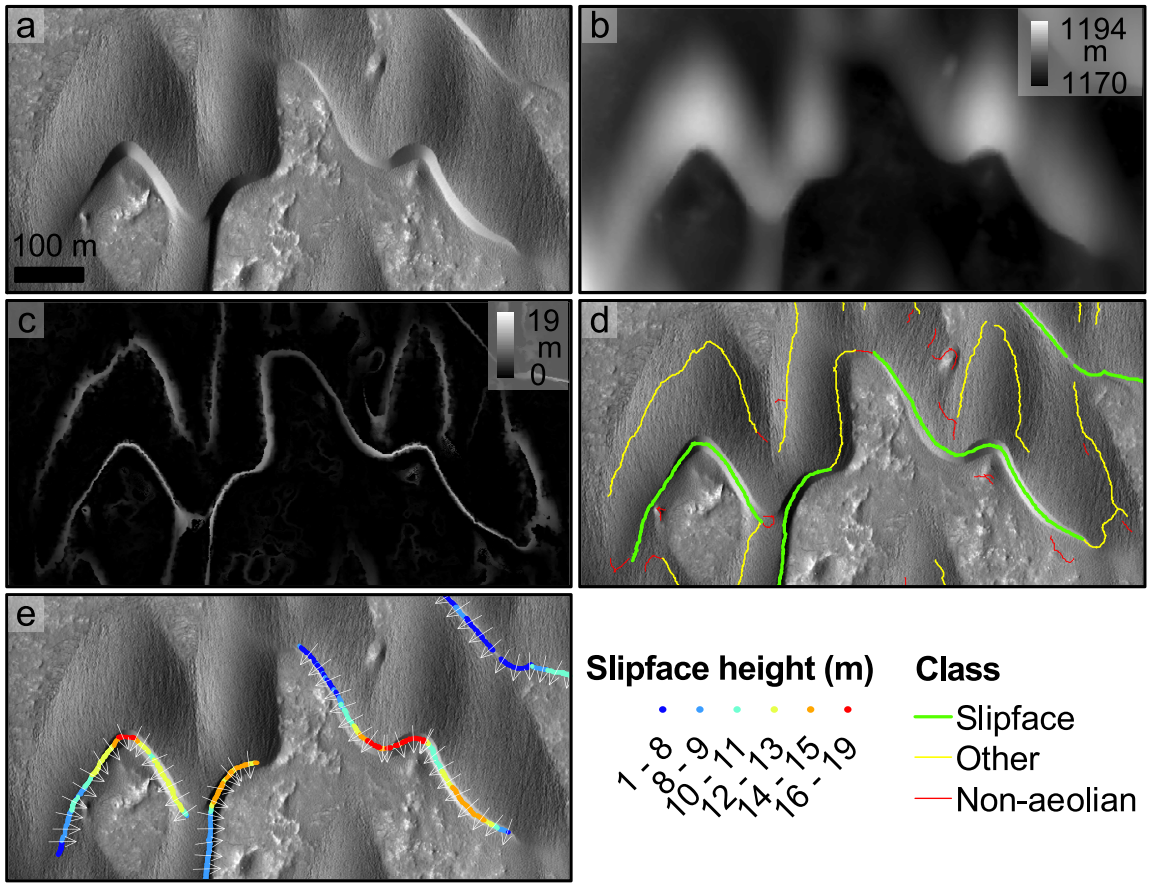

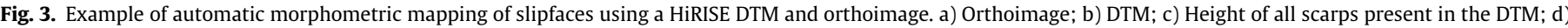

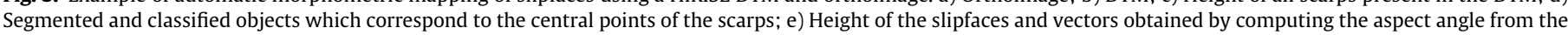
DTM (these vectors are used as local proxies for the direction of the avalanching).
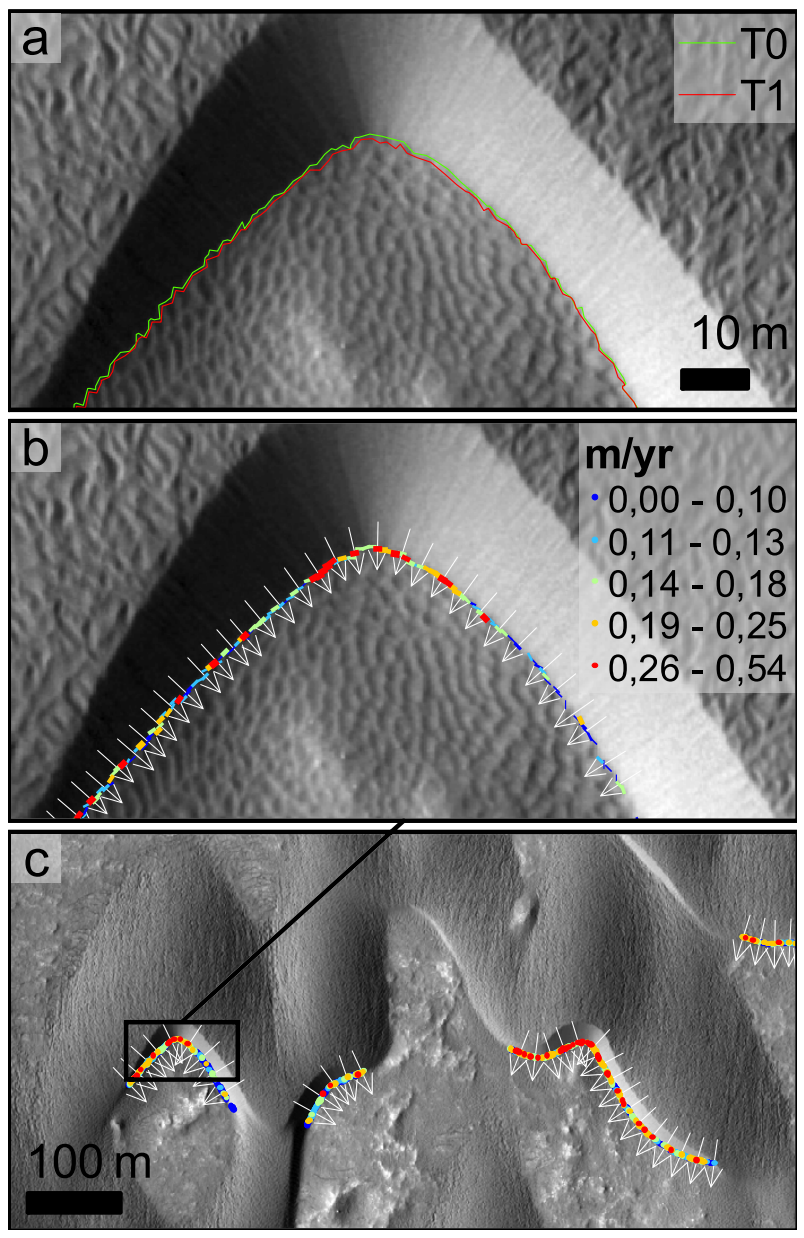

Fig. 4. Example computed lee front migration vectorial field. a) Location of the lee front lines at T0 and T1. b) Detail of the migration rates. c) Overview of a larger area, note how the measured migration rates vary along the slipfaces. bedform object, thus providing the morphometric context associated with each set of ripples.

COSI-corr software (Leprince et al., 2007) was used to orthorectify the T1 image and to generate displacement maps measuring the migration of the ripples (Bridges et al., 2012; Ayoub et al., 2014) (Fig. 5e). We use the same dataset of Cardinale et al. (2016) and exclude areas where displacements were too high to permit correlations between T0 and T1. These areas only correspond to the higher sections of the barchans located in the northern edge of the study dune field.

To evaluate the degree of wind exposure to putative wind directions we use the HiRISE DTM to compute a wind effect model (Winstral et al., 2002) providing a relative wind effect index (>1 for wind exposed areas and $<1$ for wind sheltered areas, Fig. $5 d$ ). The model requires two inputs: 1 ) the search length which controls the scale of analysis (Bohner and Antonic, 2009) and 2) wind direction. The outputs of this model for search distances of 20 and $200 \mathrm{~m}$ (approximately the maximum horizontal extents of the slipfaces and stoss slopes of the barchans in this region) and for winds blowing toward $180 \pm 30^{\circ}$ are averaged. This wind directional range was chosen considering the relatively widespread sediment transport trends inferred from the stereographic projection of the slipface surfaces (Fig. 2d in Cardinale et al., 2016).

The final output is a data grid which integrates pattern proprieties, migration quantification, morphometric setting and modeled wind effect. As we show in the following sections, this sparse representation of a large variety of datasets is ideal to discriminate and assess the dynamic behavior of Martian ripples.

\subsection{Exploratory multi-scale spatial analysis}

The spatial analysis of dune field patterns and other aeolian bedforms at different scales has been recognized as a useful way to reconstruct environmental settings (Nielson and Kocurek, 1987; Ewing et al., 2015). However, the gap between an objective quantification, pattern classification and geomorphologic significance of the different patterns is still not well established 

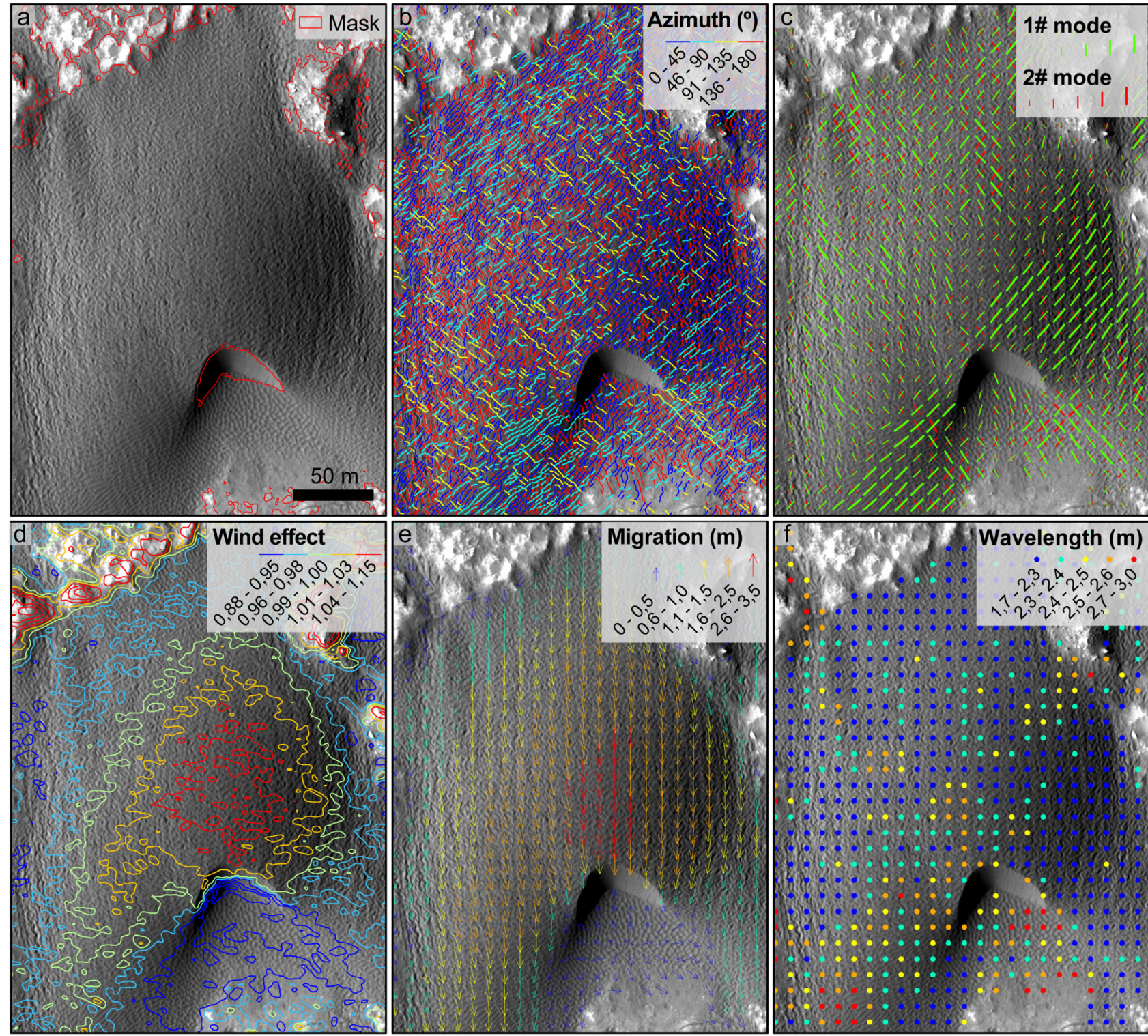

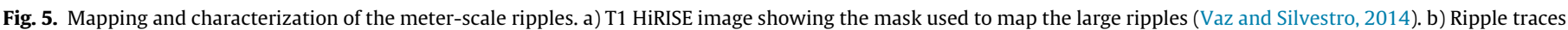

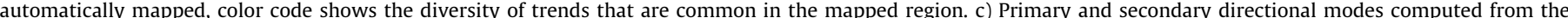

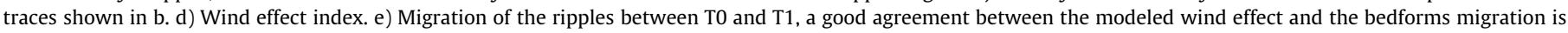

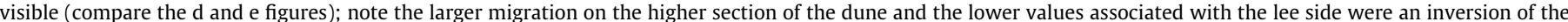

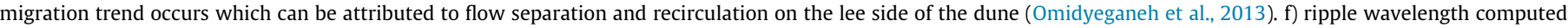
from the mapped traces (Vaz and Silvestro, 2014).

(Hugenholtz et al., 2012). In order to overcome these issues we use principal component analysis (PCA) and data clustering to: 1) map spatial variations and identify the most significant dune and ripples pattern characteristics; 2 ) segment the mapped morphologies; 3 ) explore the relations between dune pattern characteristics and topography; and 4) understand the settings and dynamics responsible for the formation of the large ripples.

\subsubsection{Dune field pattern clustering}

The grid obtained from the mapped dune elements (Fig. 2) combines several pattern attributes (Vaz et al., 2015a), which are here used to perform a principal component analysis. As specified in Section 2.1, we only use those attributes that characterize the length and the directional distribution of the mapped dune elements, also including the trend and proprieties of the primary kernel mode (see Table 1). Scalar inputs are first normalized, while for the axial data (the trend of the primary mode) the N-S and E-W components are used after doubling the azimuth angle.

The first three principal components, which account for $80 \%$ of the variance, are used to perform a k-mean clustering (Tso and Mather, 2001) with three output clusters. This number of output clusters was iteratively defined, by comparing the obtained cluster boundaries with the dune patterns in map view. This procedure generates a partition of the dune patterns emphasizing spatial variations of the dune morphologies, and as it will be shown can be used to test possible relations between large scale topography and dune patterns (Section 3.1).

\subsubsection{Ripple segmentation and clustering}

A different approach was followed for the segmentation of the ripple patterns. Simple metric relations can be used to discriminate ripples, such as the ratio between the wavelength and the height 
(vertical form index) and the horizontal form index (herein referred to as $\mathrm{H}$-index) which corresponds to the ratio between the length and wavelength of the ripples (Allen, 1968).

Since we cannot resolve the height of the ripples from the HiRISE DTM we are limited to use the H-index, which is here also applied for comparative purposes with terrestrial bedforms. In practical terms, the H-index evaluates the degree of straightness and map view regularity of the pattern. Taking advantage of the multi-temporal coverage and of the directional characterization permitted by our mapping method, we can build upon the traditional $\mathrm{H}$-index and introduce a modified $\mathrm{H}$-index $\left(M H_{\text {ind }}\right.$ in Eq. (1)).

$M H_{\text {ind }}=\frac{\sum_{t=1}^{n} \bar{R}_{t}}{\sum_{t=1}^{n} \lambda_{\mathrm{t}}} \times\left(1-\frac{1}{n} \sum_{t=1}^{n} K r_{\mathrm{t}}\right)$

where $\bar{R}_{t}$ is the magnitude of the mean length-weighted vector for a given time/image $t, \lambda$ corresponds to the median wavelength and $\mathrm{Kr}$ is the kernel modal ratio computed according to the method described in (Vaz et al., 2015a).

Time-averaging of the pattern characteristics in this modified index is used to reflect the time invariance of patterns. Indeed, while large ripples migrate and may present lateral spatial transitions, the degree of pattern straightness in a given area does not necessary change. We do not compute $M H_{\text {ind }}$ for each individual bedform trace, but for an area around each grid node (e.g., Fig. 6). This approach is consistent with the notion of ripple trains as proposed by Allen (1968) where, instead of analyzing individual ripples, assemblages of similar bedforms are used for the definition of the different patterns.

A threshold value is used to segment the large ripples in two classes, which we refer to as $2 \mathrm{D}$ class $\left(M H_{\text {ind }} \geqslant 2\right)$ and 3D class $\left(M H_{\text {ind }}<2\right)$, corresponding to the patterns which are more twodimensional (sets of ripples presenting long and regular crests) or three-dimensional (shorter and irregular patterns). As defined by Allen (1968), this dimensional classification has other implications which however cannot be tested in our analysis. Namely, we are ignoring the height of the ripples (2D patterns usually imply a constant height along the span of the bedforms) and the angle between the ripples and the flow direction is not precisely known (the crests of 3D patterns are not necessarily orthogonal to the flow direction; Allen, 1968). Even so, the spatial resolution of the HiRISE imagery is high enough to evaluate the degree of continuity of the structures, while the derived migration vectors can provide a timeaveraged representation of the flow direction.

To study the settings and probable conditions that are linked to the formation and migration of the $2 \mathrm{D}$ meter-scale ripples, we adopted the same approach used for the dune patterns, which includes PCA and clustering of this subset of bedforms. In this case, the input parameters used for the PCA were the primary directional mode, $\mathrm{H}$-index, average migration magnitude, wind effect index and the slope and aspect angles computed from the DTM. The first four principal components which account for $\sim 87 \%$ of the variance are used for the clustering, allowing the segmentation of four clusters.

\subsubsection{Ripple trend deflection}

Howard (1977) recognized dune slope as a factor that can produce relevant deviations in the ripple trends, therefore in order to assess the true obliquity of the ripples we must account for a slope correction. Eq. (2) was established from the study of ripples on barchan dunes, relating: the bed slope $(\theta)$, the angle between the surface wind and the dip angle of the slope $(\gamma)$ and the angle between the normal to the ripple trend and the surface winds $(\beta)$ (Howard, 1977).

$\sin \beta=\frac{\tan \theta \sin \gamma}{\tan 30.5^{\circ}}$

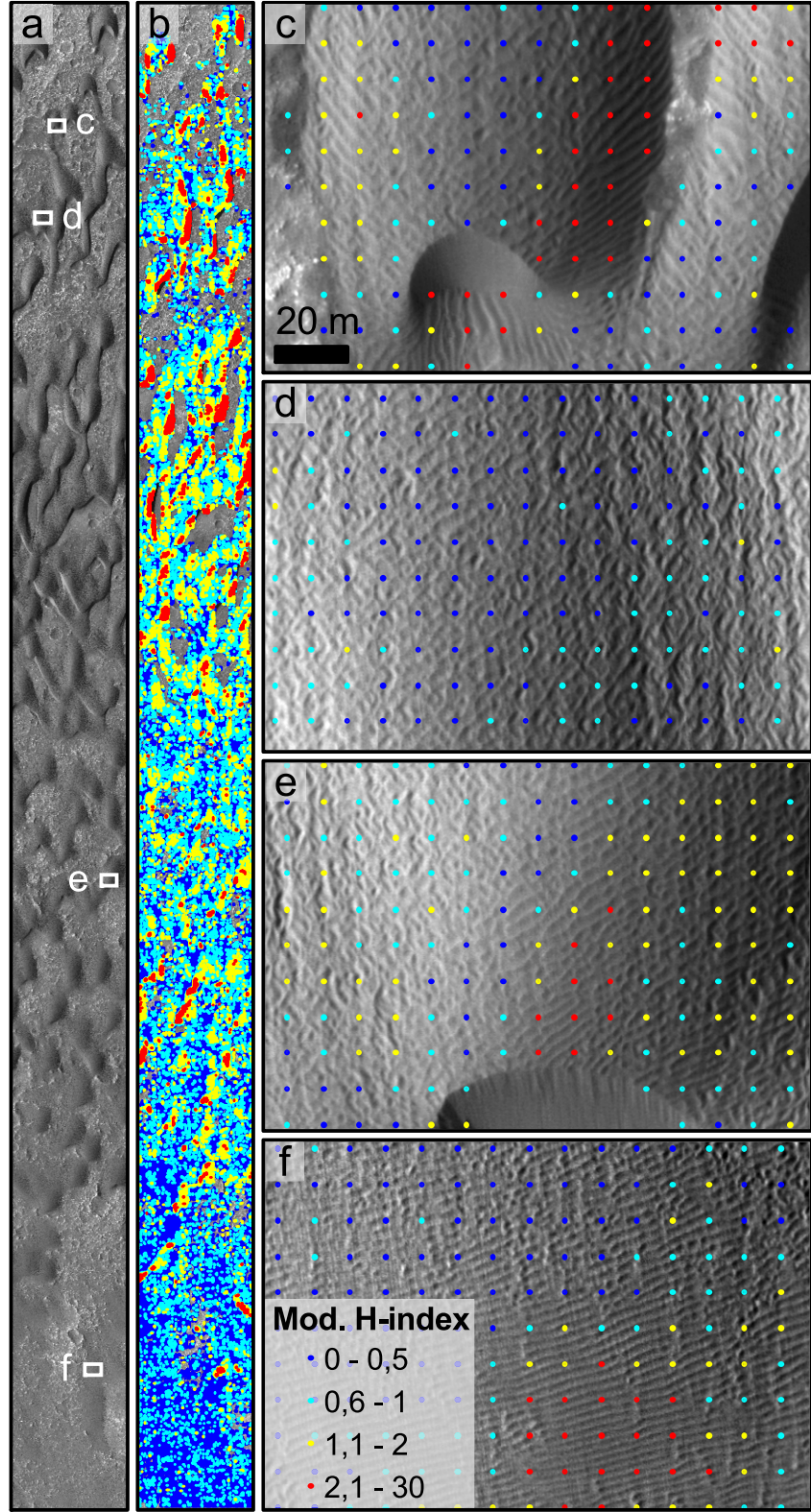

Fig. 6. Modified horizontal form index, note how straight and regular ripples assemblages correspond to higher $M H_{\text {ind }}$ values. a) Mapped region. b) Note the N-S spatial variation of this parameter, denoting a non-uniform distribution of the patterns. c) Straighter and more regular ripples arrays commonly appear associated with the leeside and flanks of the barchans. d) Example of the three-dimensional assemblages which constitute the most abundant pattern. e) In this case, note the association of the higher values with the ripples sets located near the brink of the dune. f) Although less abundant, the $2 \mathrm{D}$ class $\left(M H_{\text {ind }} \geqslant 2\right)$ is also present in the southern sand sheet, also note the transition between the 3D and 2D patterns.

The $30.5^{\circ}$ angle in the denominator represents the friction angle of sand particles and was established by Howard (1977) by finding the best fit to field data. The friction angle of sand on Mars could be slightly different, owing to more angular grains and multi-mineral composition (basaltic) compared to well rounded quartz sand on Earth. Even so, the dip angle of slipfaces (a proxy for friction angle) on Mars is $\sim 30^{\circ}$ (Atwood-Stone and McEwen, 2013; Silvestro et al., 2013), similar to terrestrial dune slipfaces. For this reason we use the same angle estimated by Howard (1977).

We have computed the slope deflections for each 2D cluster located in the windward side of the dunes, assuming a wind flow towards the south and using the average aspect angle and the mean and maximum slopes for each cluster (Table 3 ). The objective 
of the computed deflection angles is to verify if the measured oblique migrations can be justified by the slope effect on the ripples trend.

\section{Results}

\subsection{Dune field pattern analysis}

The mapping and PCA analysis of the dune patterns in the region provides the necessary context for the more detailed analysis of the meter-scale ripples. In Table 1 we show that the density of the mapped dune elements is the main contributor for the variance of the patterns. The first component (PC1) accounts for $40 \%$ of the pattern variance and is best correlated with the total number of mapped features and with the kernel frequency. Since the kernel frequency corresponds to a directional sum of the features length (Vaz et al., 2015a), PC1 is also dependent on the number/density of mapped features. The other most relevant parameters are the length, azimuth and the modal ratio of the mapped features,

\section{Table 1}

Correlations between the dune field descriptors and the principal component scores. $\bar{R}_{L}$ is the length-weighted mean vector magnitude; CSTD is the circular standard deviation; $k_{\text {mode } 1}$ and $k_{\text {freq } 1}$ correspond to the azimuth and frequency of the primary kernel modes (Vaz et al., 2015a); $k_{\text {mrat }}$ is the modal ratio; $\bar{L}, s_{L}$ and $\operatorname{med}_{L}$ are respectively the mean, standard deviation and median length; $n_{\text {all }}$ corresponds to the total number of aeolian features and $n_{\text {slipfaces }}$ to the number of features classified as slipfaces. Bold type indicates the two most relevant parameters for each component.

\begin{tabular}{llllll}
\hline & PC \#1 & PC \#2 & PC \#3 & PC \#4 & PC \#5 \\
\hline $\bar{R}_{L}$ & 0.10 & $\mathbf{0 . 4 2}$ & -0.12 & -0.06 & 0.28 \\
CSTD & -0.14 & -0.26 & 0.20 & -0.22 & -0.27 \\
cos $k_{\text {mode } 1}$ & 0.13 & 0.16 & -0.05 & $\mathbf{0 . 5 5}$ & $\mathbf{0 . 5 6}$ \\
$\sin k_{\text {mode } 1}$ & -0.10 & $\mathbf{0 . 4 6}$ & $\mathbf{0 . 6 0}$ & $\mathbf{0 . 4 7}$ & -0.43 \\
$k_{\text {freq } 1}$ & $\mathbf{0 . 5 0}$ & 0.05 & 0.17 & -0.09 & 0.08 \\
$k_{\text {mrat }}$ & -0.46 & -0.24 & $\mathbf{0 . 6 0}$ & -0.11 & $\mathbf{0 . 5 5}$ \\
$\bar{L}$ & -0.03 & 0.39 & 0.08 & -0.41 & 0.08 \\
$s_{L}$ & 0.12 & 0.34 & 0.17 & -0.38 & -0.05 \\
med $_{L}$ & -0.10 & 0.33 & 0.01 & -0.30 & 0.17 \\
$n_{\text {all }}$ & $\mathbf{0 . 5 0}$ & -0.18 & 0.26 & -0.04 & 0.08 \\
$n_{\text {slipfaces }}$ & 0.45 & -0.22 & 0.31 & -0.06 & 0.04 \\
\% explained variance & 40.25 & 26.12 & 13.82 & 7.91 & 5.76 \\
\hline
\end{tabular}

contributing for the second and third components (26 and $14 \%$ of the variance respectively).

The map view of the principal component scores (Fig. 7) show clear spatial transitions, denoting a regional $\sim \mathrm{NW}$-SE decrease of PC1 (Fig. 7a). A regional $\sim \mathrm{N}-\mathrm{S}$ wind regime and a $162 \pm 38^{\circ}$ direction of slipface migration were reported by Cardinale et al. (2016) in the area for which we have HiRISE coverage (delimited in white). Extrapolating these generic trends of wind and sediment transport to all the mapped dune fields we can associate this largescale pattern variation (mainly related with the density of dune elements) with an upwind/downwind transition of the dune patterns. Another major pattern spatial variation can be seen from PC2 (Fig. 7b), with a regional $\sim$ NE-SW decrease of the component values. Note that this transition occurs over the detailed study area and is mainly related to variations in the trend of the mapped dune elements (Table 1). A better view of this transition is given in Fig. $8 \mathrm{~b}$ and $\mathrm{c}$.

The spatial variation of PC3 (Fig. 7c) is more difficult to interpret, but from Table 1 we conclude that higher scores are related with higher modal ratios, implying a higher degree of directional bimodality. This is more obvious when analyzing the mapped slipface traces (Fig. 8c), where regions with bimodal slipface orientations are visible.

The dune clustering (Fig. 8a) together with the directional modes (Fig. 8b and c) synthesize much of what was previously discussed, namely the spatial variations of the principal components. Displaying the regional topography together with the mapped trends and clusters offer a different perspective as it shows how topography may control the dune patterns. In the mapped region, a NW-SE trending plateau with $\sim 400 \mathrm{~m}$ high is located between the southern and northern dune fields. The study dune fields are located in depressions that pass to higher terrains towards the SE. The clusters mapped in the southern dune field can be easily associated with specific dune sets: 1 ) cluster I corresponds to sets of elongated asymmetric barchans and barchanoids (Fig. 2c and f) whose horns and slipfaces are nearly parallel to the mentioned plateau suggesting a possible genetic relation (wind flow bimodality induced by the topography can lead to barchan horn elongation; Parteli et al., 2014); 2) cluster II corresponds to a sand sheet presenting lower density of dune elements, in most of the cases lacking visible slipfaces (dome dunes); 3) and cluster III corresponds to
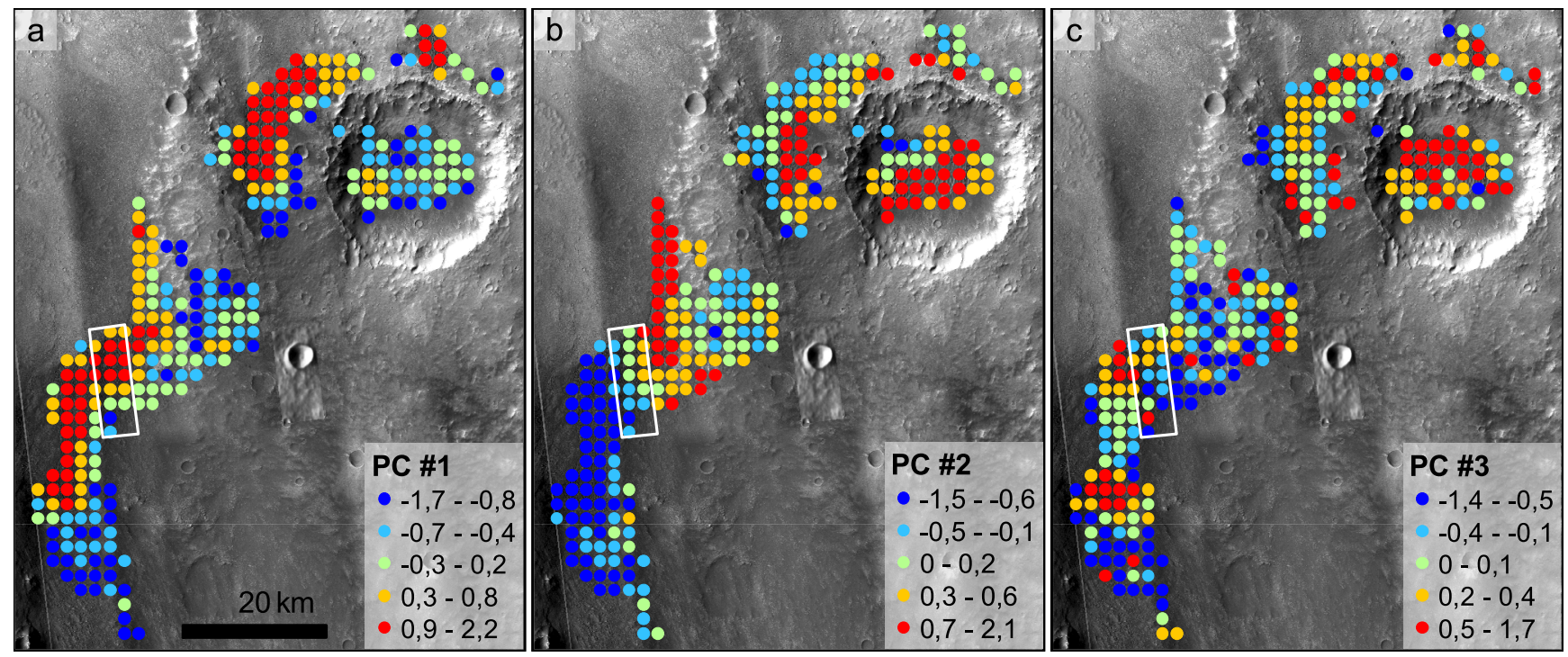

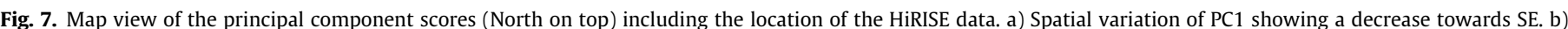

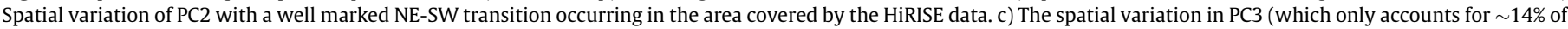
the variance) is fuzzier, but from Table 1 we know that it is related to the trend and degree of bimodality of the mapped dune features (compare with Fig. $8 \mathrm{c}$ ). 

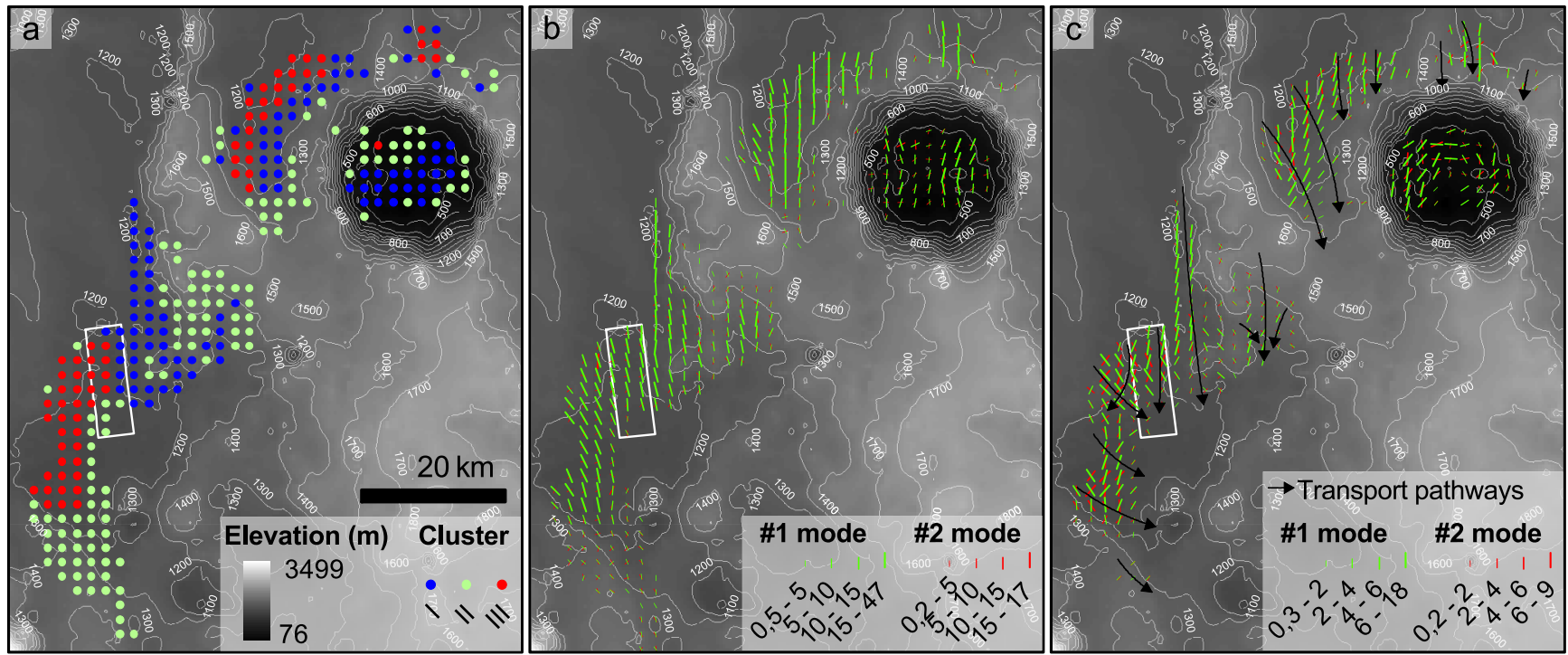

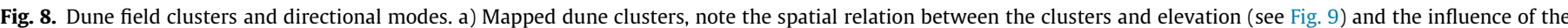

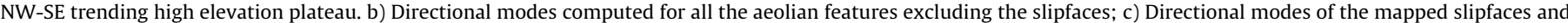
inferred sediment transport pathways, note the areas with bimodal slipface trends.

the barchans and barchanoids (Fig. 2b and d) located in the western edge of the dune field which can present more than one set of slipfaces suggesting variable prevailing winds. Putative transport pathways are presented in Fig. 8c, showing the primary N-S direction of sediment transport and a W-E transport component located in the western section of the dune field, an area where wind models predict secondary winds blowing from the crater rim (Cardinale et al., 2016). On the floor of the impact crater located to the NE in the study area, the slipfaces form a concentric pattern typical of Martian "bullseye" dune fields (Fenton and Hayward, 2010).

As mentioned, the clustering only uses the map view proprieties and geometry of the dune elements. This means that it can be used to test possible relations between dune patterns and wind models' outputs or topography (Vaz et al., 2015a). For the mapped region, a moderate negative correlation $(r=-0.55, p<0.001)$ between the density of mapped morphologies (the parameter that contributes more to the pattern variance) and elevation is found (Fig. 9). This relation is only valid for the dunes located outside the impact crater with a "bullseye" dune field, demonstrating that the formation of this type of patterns is controlled by a very different topography/wind interaction. What is more relevant is that the segmented clusters also possess different elevation signatures, with cluster III associated with lower terrains (average elevation of $1212 \pm 54 \mathrm{~m}$ ) and clusters I and II with increasing elevations (1264 \pm 61 and $1316 \pm 94 \mathrm{~m}$ respectively). This demonstrates an effective association between dune patterns and topography. It is out of the scope of this paper to investigate and prove the reasons for this relation in the case of Herschel, but it is known from our planet that long-wavelength topography influences wind flow, sediment availability and/or dune field roughness, factors that can control dune patterns at large spatial scales (Jerolmack et al., 2012; du Pont et al., 2014; Pelletier, 2015).

\subsection{Dune morphometry and migration}

At a finer scale and using the HiRISE DTM we are able to quantify the spatial variations of the slipface morphology and migration rates along the dune field (Fig. 10). A simple visual analysis of the mapped features shows a southward decrease of the number and complexity of morphologies (Fig. 10b) which is in agreement with the results previously presented (namely the spatial variation of PC1, Fig. 7a). However, the spatial distribution of the slipface heights and migration rates presents a higher degree of complexity, including: 1) a first-order N-S decrease of slipface height and migration (already noted in Cardinale et al., 2016); 2) a second order topographic control consisting in the decrease of the slipface height when approaching the topographic high $(\sim 30 \mathrm{~m})$ marked as $\mathrm{A}$ (note the correspondent migration speedup in the windward side and slow down in the leeside) and the increase of the height of the slipfaces in the leeside of this obstacle (Fig. 10c); 3) with the lateral

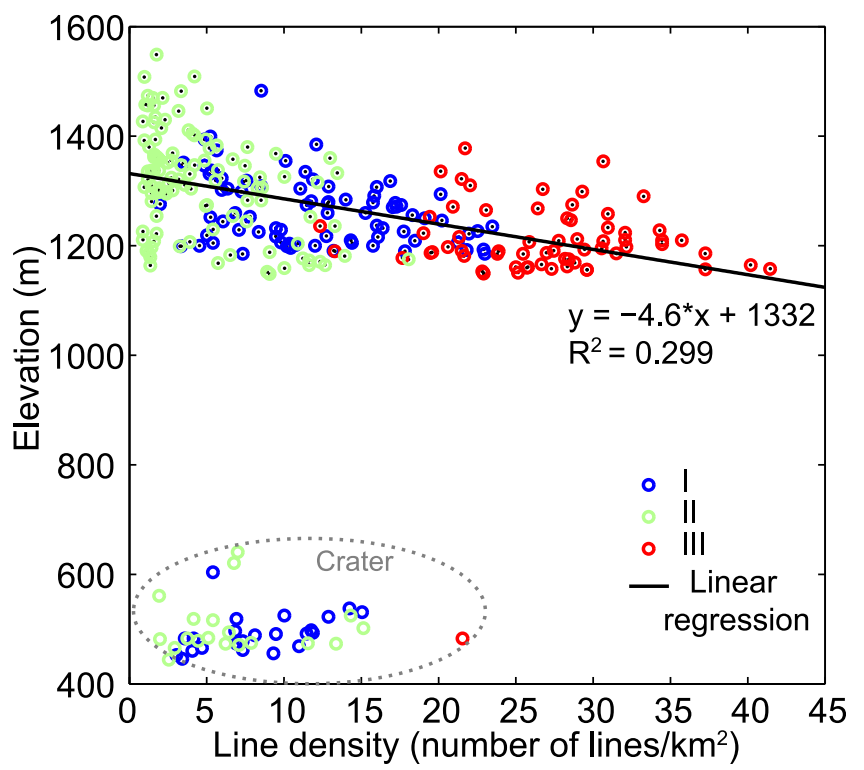

Fig. 9. Linear regression between elevation and the density of mapped dune features. Excluding the dunes located inside the crater (NE corner of the area), a possible linear relation between elevation and morphology density is observed. Note the preferential association of cluster II and III with higher and lower elevations respectively. 

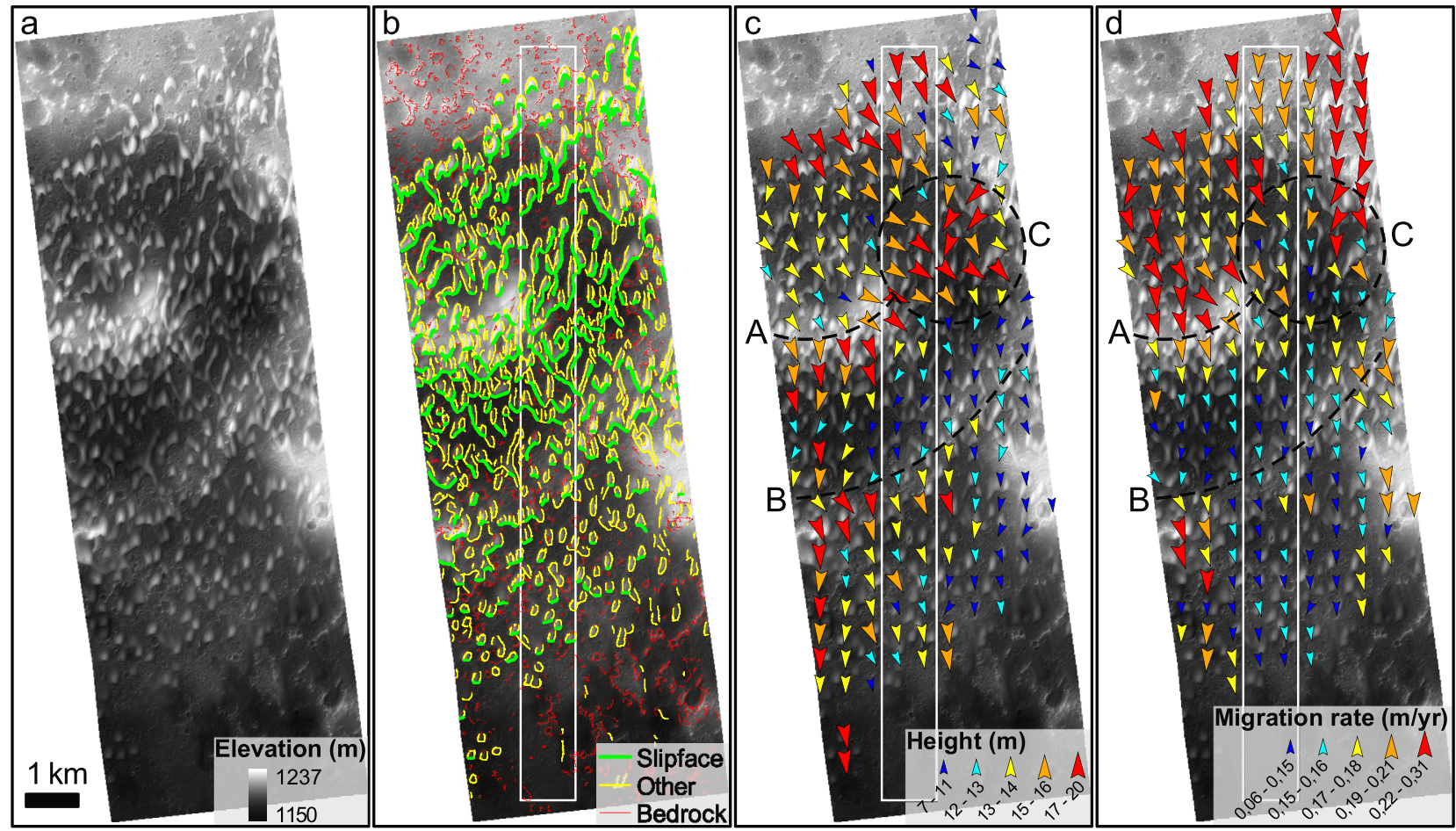

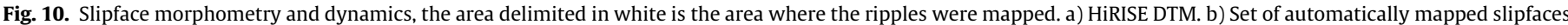

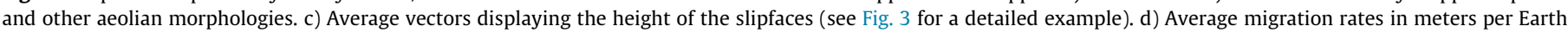

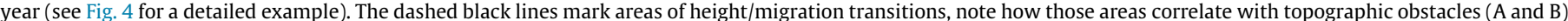
and the influence of these obstacles in the trend of the vectors (C). Note the migration speedup in the windward side and subsequent deceleration in the leeside of $\mathrm{A}$.

attenuation of this topographic high towards the east, we note the warping, convergence and reduction of the migration rates in the area marked with $\mathrm{C}$ which corresponds to a depression where higher slipfaces occur; 4) further south a more subtle topographic step $\sim 10 \mathrm{~m}$ high and marked with $\mathrm{B}$, also seems to influence the measured slipface attributes, although in this case the migration acceleration occurs after the topographic transition (Fig. 10d). The impact of topography on the morphometry and dynamics of the dunes is noticeable, overprinting $\mathrm{km}$-scale variations in the trend, height and migration rate of the dune's slipfaces. As it will be discussed in the following sections, the described dune morphodynamic variations play an important role on the spatial distribution of the meter-scale ripples, whose analysis is the main purpose of this paper.

\subsection{Ripple mapping and clustering}

Perhaps the most important result of the large ripple mapping is the quantification of the relative abundance of $2 \mathrm{D}$ and 3D patterns. The described segmentation using the modified H-index revealed that the vast majority of the ripples correspond to the $3 \mathrm{D}$ class ( $97.3 \%$ of the mapped area). The set of 3D ripples is widespread over the dunes, presenting interlaced morphologies (e.g., Fig. $11 \mathrm{~b})$ with bimodal trends $\left(45^{\circ}\right.$ and $150^{\circ}$, Fig. $11 \mathrm{a}$ and $\left.\mathrm{b}\right)$ and southward migration direction (1.1 $\mathrm{m}$ on average, Fig. 11c and d). These proprieties suggest that the 3D patterns are composed by oblique elements that display a higher degree of complexity. By analogy with 3D subaqueous dunes, these morphologies may also include linguoid or lunate elements, spurs and scour pits (Costello and Southard, 1981), features which cannot be easily discriminated with HiRISE data.

The segmented 3D patterns are treated here as a uniform set of bedforms, but clear pattern variations also exist inside this sub-population (compare for instance the 3D patterns in Figs. $6 \mathrm{~d}, \mathrm{f}$ and $11 \mathrm{~b}$ ). For simplicity we are only performing the cluster analysis for the 2D patterns, characterizing the spatial context associated with this type of meter-scale ripples. A similar approach applied to the 3D set would probably produce the same type of results, allowing the segmentation of the different patterns and constraining the settings where they preferentially occur.

Only $2.7 \%$ of the mapped area corresponds to the 2D set, in addition Fig. 12a clearly shows that the spatial distribution of the segmented 2D large ripples is not uniform. The density of 2D features is higher in the northern half of the mapped region (Fig. 13); while in the southern half the density of 2D ripples decreases. The same general N-S tendency was observed for the slipface migration rates (Fig. 10d), suggesting a link between sediment flux at a dune scale, dune morphology and the occurrence of the $2 \mathrm{D}$ patterns. A good example of this relation is the slipface morphometric transition marked as B (Fig. 10c), which also corresponds to a large decrease in the number of 2D meter-scale ripples (Fig. 13).

The PCA analysis shows that the trend and the aspect angle of the surface where the meter-scale ripples are located explain most of the pattern variance (Table 2 ). The pattern migration rate and surface slope are the other key parameters. The map view and statistical analysis of the segmented clusters enables the precise definition of the preferential settings where the $2 \mathrm{D}$ patterns occur.

Large ripples that belong to cluster I (63\% of the 2D subpopulation, Table 3 ) are preferentially located in surfaces facing East and with average slopes of $17^{\circ}$ (up to maximum slopes of $25^{\circ}$, Fig. 14a). They present the higher $\mathrm{H}$-index values, are the $2 \mathrm{D}$ patterns more exposed to the modeled wind trends (Fig. 14d) and the average migration of this set of ripples was $1.9 \mathrm{~m}$ (the highest migration of all mapped clusters). These bedforms are 

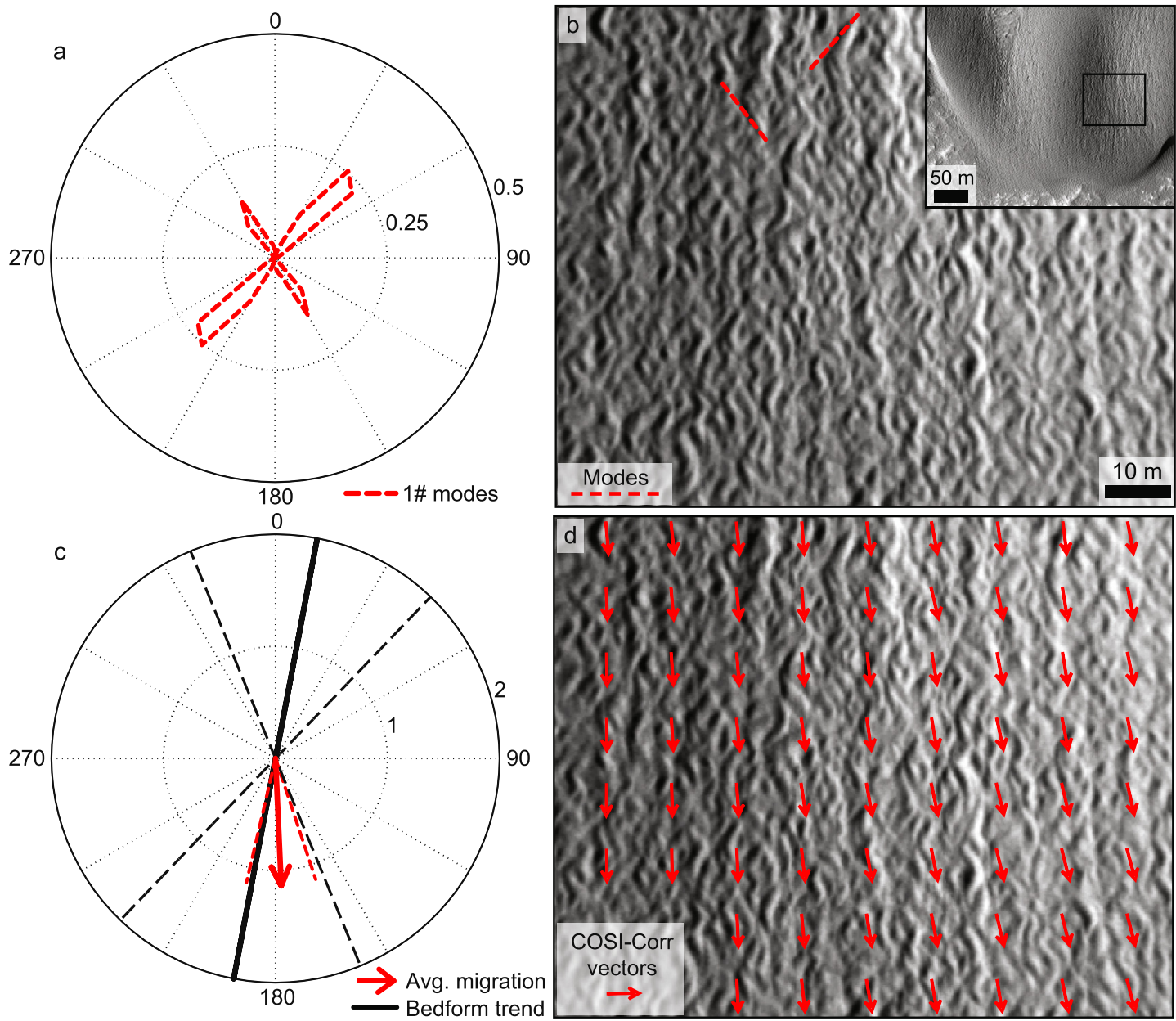

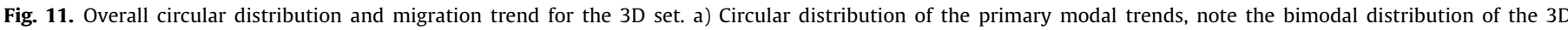

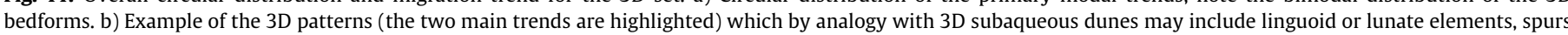

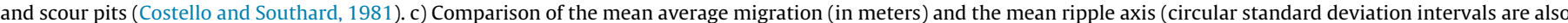
shown). d) Migration trends for the same area shown in b.

preferentially located in the eastern flanks of barchans (Fig. 12c) and in rippled slipfaces associated with elongated asymmetric barchanoids (Fig. 12b). The area with higher concentration of cluster I large ripples matches the area where slipface migration is warped (area C in Figs. 10c and 13).

Cluster II corresponds to dune surfaces facing the West and also presenting relatively high slope angles (average of $17^{\circ}$ with maximum slopes up to $20^{\circ}$, Fig. 14a). Compared with cluster I, it presents lower $\mathrm{H}$-index and wind effect values, also corresponding to a lower migration (Fig. 14b). Since cluster II ripples also appear in the same type of preferential settings (barchan flanks, Fig. 12b and c), we interpret cluster I and II as conjugated sets of bedforms. Nevertheless, cluster II ripples are much less common (only $8 \%$ of the 2D set) and are spatially restricted to the northern half of the mapped area (Figs. 12a and 13), a spatial distribution equivalent to the location of faster migrating dunes (Fig. 10d).

A common property of clusters I and II is the large angular deviation from a pure transverse migration of the meter-scale ripples (average obliquity of 66 and $53^{\circ}$ towards the South quadrant respectively, see Fig. $14 \mathrm{~b}$ and Table 3 ). The predicted average slope deflection for each cluster is not enough to account for this high degree of obliquity, since it can only explain half of the observed deflection (after subtracting the theoretical slope effect we still have deflection angles of 22 and $35^{\circ}$ respectively). Only for the extreme high slopes $\left(25^{\circ}\right)$ in cluster I the predicted slope effect $\left(52^{\circ}\right)$ is able to justify the observed obliquity.

Cluster III corresponds to a very different dune setting, located on gentle SE dipping surfaces ( $9^{\circ}$ of average slope) and with ripples trending NE-SW (Fig. 14a and b). The examples in Fig. 10 show that this cluster appears associated with the flatter areas on the top of the dunes, located between the crest and the brink. We measured intermediate migrations and wind effects for these locations. The cluster appears scattered throughout the area, but it becomes the predominant 2D pattern in the southern edge of the dune field (Fig. 13) where it develops on the leeside section of dome dunes. As for clusters I and II, the migration of cluster III is oblique to the large ripples trend. A deflection from the orthogonal migration of $45^{\circ}$ was estimated with a predicted slope deflection that cannot totally explain the measured obliquity (Table 3 ).

The last cluster is perhaps the one which is easier to relate with a specific dune setting. Cluster IV evolves in lower dune elevations (Table 3$)$ with gentle slopes $\left(6^{\circ}\right)$ dipping preferentially south. Crestline's orientation is mainly N-S. The modeled wind effect values ( $<1$, Fig. 14 d) show that cluster IV is located in areas which are sheltered from the direct action of the winds, in accordance with the very low average migration associated with this set of bedforms. Despite the relative large dispersion of the migration trends (recall for instance Fig. 5e) we measured an average migration 

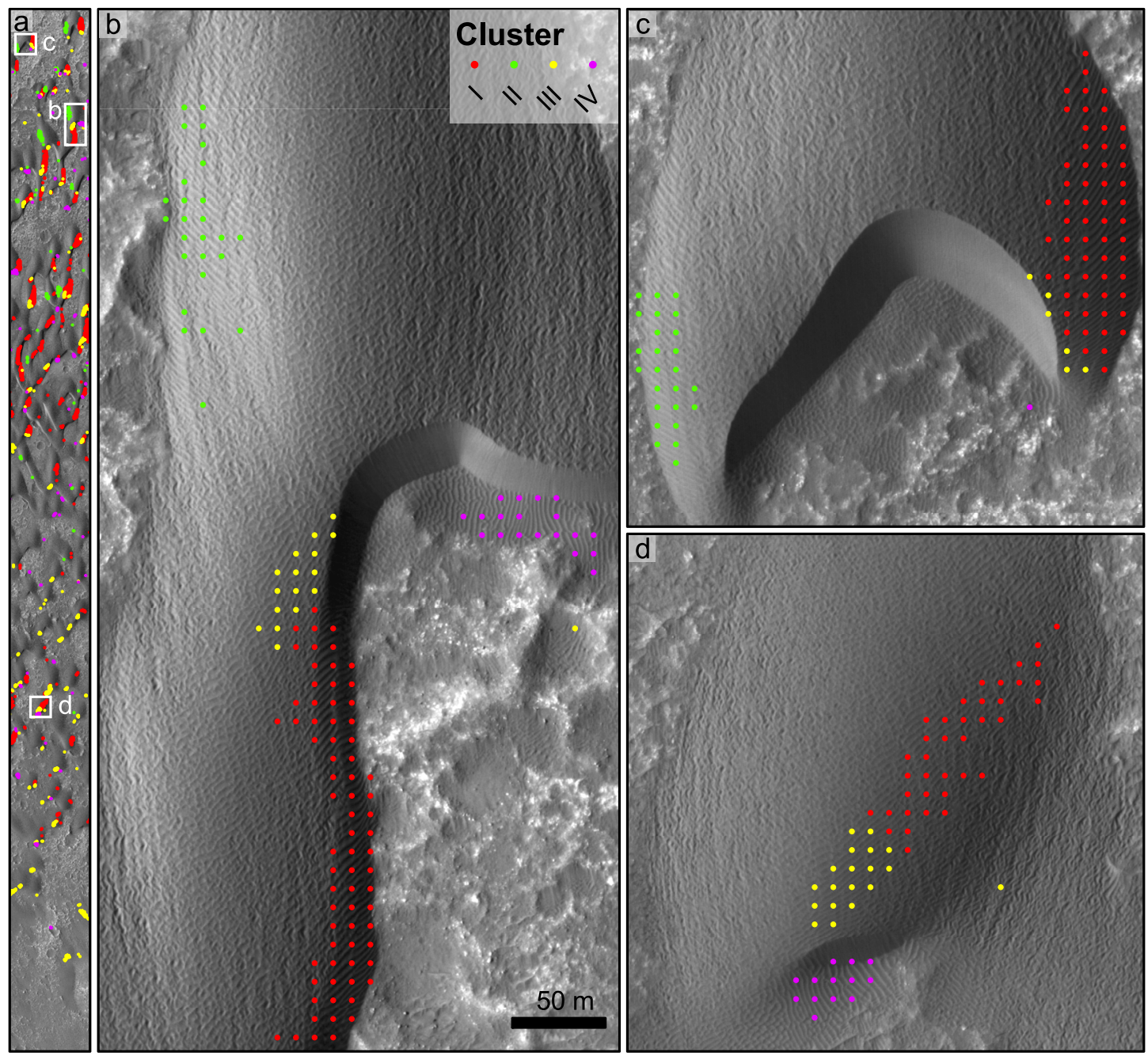

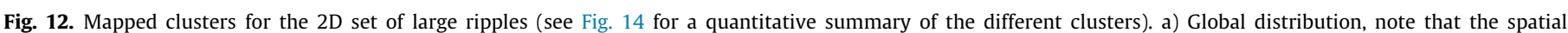

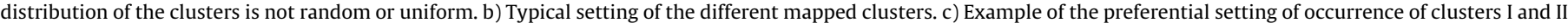
in the flanks of barchans. d) Example of the preferential setting of occurrence of the clusters III (between the crest and brink) and IV (in the leeside of the dunes).

vector with the same orientation of the large ripples, indicating longitudinal transport along the bedforms. A clear association of this cluster with low areas on the leeside of the dunes or bedrock obstacles can be seen in Fig. 12.

\subsubsection{Bedform H-index comparison}

In the absence of reliable height-wavelength measurements for the Martian bedforms, the $\mathrm{H}$-index allows a direct morphological comparison of bedforms. The 3D set of ripples present lower H-index values $(3.1 \pm 0.5)$, while the several identified $2 \mathrm{D}$ sets show higher but variable values (Fig. 14c). Overall, the mapped large-scale ripples on Herschel have values of H-index in the 335 range, for wavelengths of $1.5-4 \mathrm{~m}$ (Fig. 15), in clear contrast with aeolian ripples on our planet, with typical $\mathrm{H}$-index values between 10 and 100 for centimetric wavelengths (Pye and Tsoar, 2009).

The meter-scale bedforms on Herschel are morphologically different from Martian intracrater TARs, but present some overlap with the plain ripples mapped by Silvestro et al. (2015a) in Meridiani Planum. Terrestrial aeolian megaripples also present similar $\mathrm{H}$-index values for lower wavelengths, although the reduce number of measurements we show are probably not representative of the variance that those bedforms present in our planet.
The H-index values for subaqueous two and three-dimensional dunes surveyed in tidal flats (Elliott and Gardiner, 1981) are similar to our measurements, although they seem to be associated with slightly higher wavelengths. In this specific case, since they formed on tidal environments these subaqueous dunes may result from very different flow configurations (bidirectional and reversing flows). Yet, this example shows the transition and overlap of 2D and 3D sets, a common characteristic that the large ripples also display.

Following the guidelines used to classify underwater bedforms (Ashley and Chairpers, 1990) we conclude that all presented Martian bedforms are morphologically akin to subaqueous dunes in terms of plan view morphology. This reinforces the idea that the stratification produced by the meter-scale ripples and by subaqueous bedforms should present similarities in scale and form, as suggested by (Lapotre et al., 2016a).

The H-index is certainly not the best parameter to segment and compare bedform morphologies, note the large overlaps in this parameters reported by (Allen, 1968) for diverse types of underwater bedforms (Fig. 15). Nevertheless this parameter still allows a direct comparison of the patterns, from where we conclude that the bulk of the segmented 2D patterns are morphologically different from terrestrial aeolian ripples and can be considered sinuous to straight bedforms. 

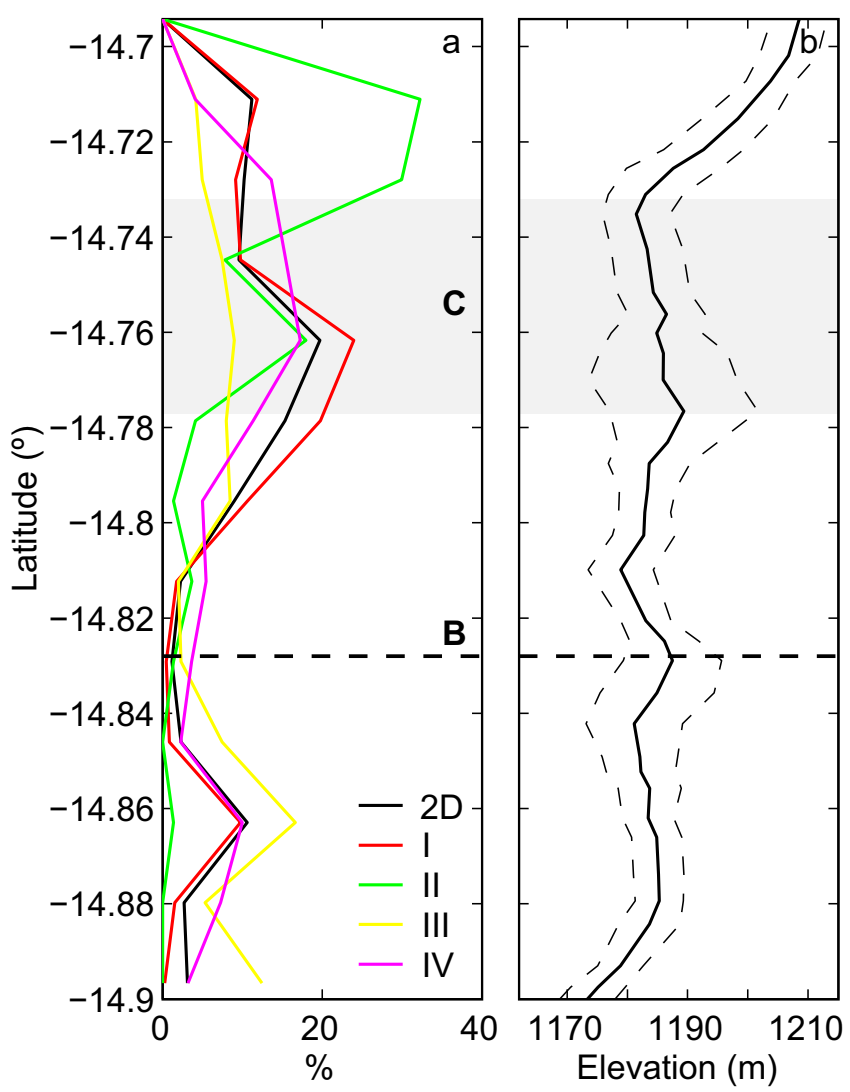

Fig. 13. Spatial distribution of the $2 \mathrm{D}$ clusters (averaged on a N-S window with $1 \mathrm{~km}$ ), the location of the main topographic discontinuities signaled in Fig. 10 are shown. a) Relative density for each cluster and for all 2D patterns. b) Clusters average elevation and standard deviation.

\section{Discussion}

The regional scale analysis shows that the dunes in the study area indicate a $\sim N N W$-SSE gross sediment transport direction, on a transitional area between $\mathrm{N}-\mathrm{S}$ transport in the west to NW-SE in the east. As demonstrated, the spatial arrangement of the dunes is strongly influenced by long-wavelength topography, which translates in the existence of a correlation between dune pattern density and elevation. The density is higher for lower elevations, which can also be related to a gravity-driven focusing of sediments to low-lying areas.

From the PCA analysis we conclude that the density of the dunes is the most important parameter to explain pattern spatial variation, presenting an upwind-downwind transition which is also recognizable on the subsequent scale of analysis. The morphodynamic analysis of the slipfaces along the dune field also reflects this $\sim \mathrm{N}-\mathrm{S}$ spatial variation which is recognizable as a first-order decrease of the height and migration rates of the dune slipfaces. The same decrease was also observed for the migration of the meter-scale bedforms (Cardinale et al., 2016), with higher migration rates on the northern border of the dune field. This type of transition, with higher sedimentary fluxes near the upwind edge of the dune field is common on terrestrial dune fields and was interpreted to be the result of a roughness transition which creates an internal boundary layer decreasing the shear stress downwind (Jerolmack et al., 2012). This view is not agreed upon; Pelletier (2015) argues in favor of a feedback between long-wavelength topography and the dunes. In the same manner, our observations demonstrate that topography plays a fundamental role causing a $\mathrm{km}$-scale spatial modulation of the dune's migration rate and morphology. An important observation is that long-wavelength topography can induce quasi-transverse coherent trends in orientation and migration rate (like between $\mathrm{A}$ and $\mathrm{B}$, Fig. 10) but also lateral ones, like observed between $\mathrm{A}$ and $\mathrm{C}$. These dune morphodynamic

Table 2

Correlation between the 2D ripples descriptors and the principal component scores. The PCA was based in the following pattern descriptors: $k_{\text {mode } 1}$ is the azimuth of the primary directional kernel mode (Vaz et al., 2015a); H-index is the horizontal form index; average migration, wind effect, slope angle $(S)$ and the aspect angle $(a)$ are the other parameters analyzed. Bold type indicates the two most relevant parameters for each component.

\begin{tabular}{|c|c|c|c|c|c|}
\hline & PC \#1 & PC \#2 & PC \#3 & PC \#4 & PC \#5 \\
\hline $\cos k_{\text {mode } 1}$ & -0.14 & 0.02 & 0.44 & -0.54 & -0.47 \\
\hline $\sin k_{\text {mode } 1}$ & 0.68 & -0.24 & -0.14 & 0.01 & 0.15 \\
\hline$H$-index & 0.06 & 0.07 & 0.03 & 0.18 & -0.20 \\
\hline Migration & 0.21 & 0.64 & -0.53 & -0.42 & -0.23 \\
\hline Wind effect & 0.13 & 0.23 & -0.11 & -0.03 & 0.42 \\
\hline$S$ & 0.15 & 0.54 & 0.28 & 0.65 & -0.30 \\
\hline $\cos a$ & 0.06 & 0.40 & 0.55 & -0.24 & 0.58 \\
\hline $\sin a$ & 0.66 & -0.16 & 0.32 & -0.13 & -0.23 \\
\hline \% explained variance & 44.66 & 17.20 & 14.99 & 10.08 & 4.99 \\
\hline
\end{tabular}

Table 3

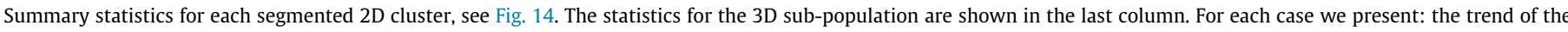

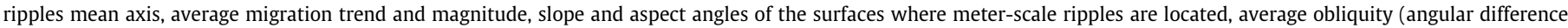

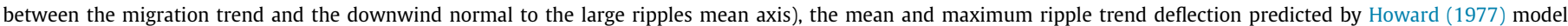

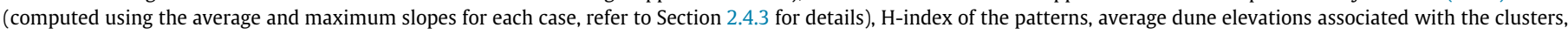
average wind effect (refer to Section 2.3) and the number of nodes in each class (N).

\begin{tabular}{|c|c|c|c|c|c|}
\hline & I & II & III & IV & $3 \mathrm{D}$ \\
\hline Mean trend $\left(^{\circ}\right)$ & $44 \pm 15$ & $142 \pm 14$ & $53 \pm 22$ & $169 \pm 27$ & $11 \pm 33$ \\
\hline Migration trend $\left(^{\circ}\right)$ & $187 \pm 25$ & $166 \pm 26$ & $188 \pm 15$ & $171 \pm 61$ & $177 \pm 16$ \\
\hline Migration magnitude (m) & 1.91 & 1.59 & 1.47 & 0.24 & 1.14 \\
\hline Aspect; Slope $\left(^{\circ}\right)$ & $97 ; 17$ & $265 ; 17$ & $148 ; 9$ & $172 ; 6$ & $\sim 80 ; 6 \mid \sim 280 ; 6$ \\
\hline Average obliquity $\left(^{\circ}\right)$ & 53 & 66 & 45 & 88 & 76 \\
\hline Mean (max.) slope deflection $\left(^{\circ}\right)$ & $31(52)$ & $31(38)$ & $8(19)$ & - & - \\
\hline H-index & $6.5 \pm 3.6$ & $4.4 \pm 0.9$ & $5.1 \pm 1.3$ & $4.9 \pm 2.5$ & $3.1 \pm 0.5$ \\
\hline Dune elevation (m) & $8.5 \pm 5.9$ & $6.3 \pm 4.5$ & $8.3 \pm 6.7$ & $1.2 \pm 1.5$ & $4.6 \pm 5.5$ \\
\hline Wind effect index & $1.01 \pm 0.03$ & $0.99 \pm 0.03$ & $0.99 \pm 0.04$ & $0.93 \pm 0.03$ & $1.0 \pm 0.04$ \\
\hline $\mathrm{N}$ & 1749 & 217 & 601 & 220 & 99,642 \\
\hline
\end{tabular}



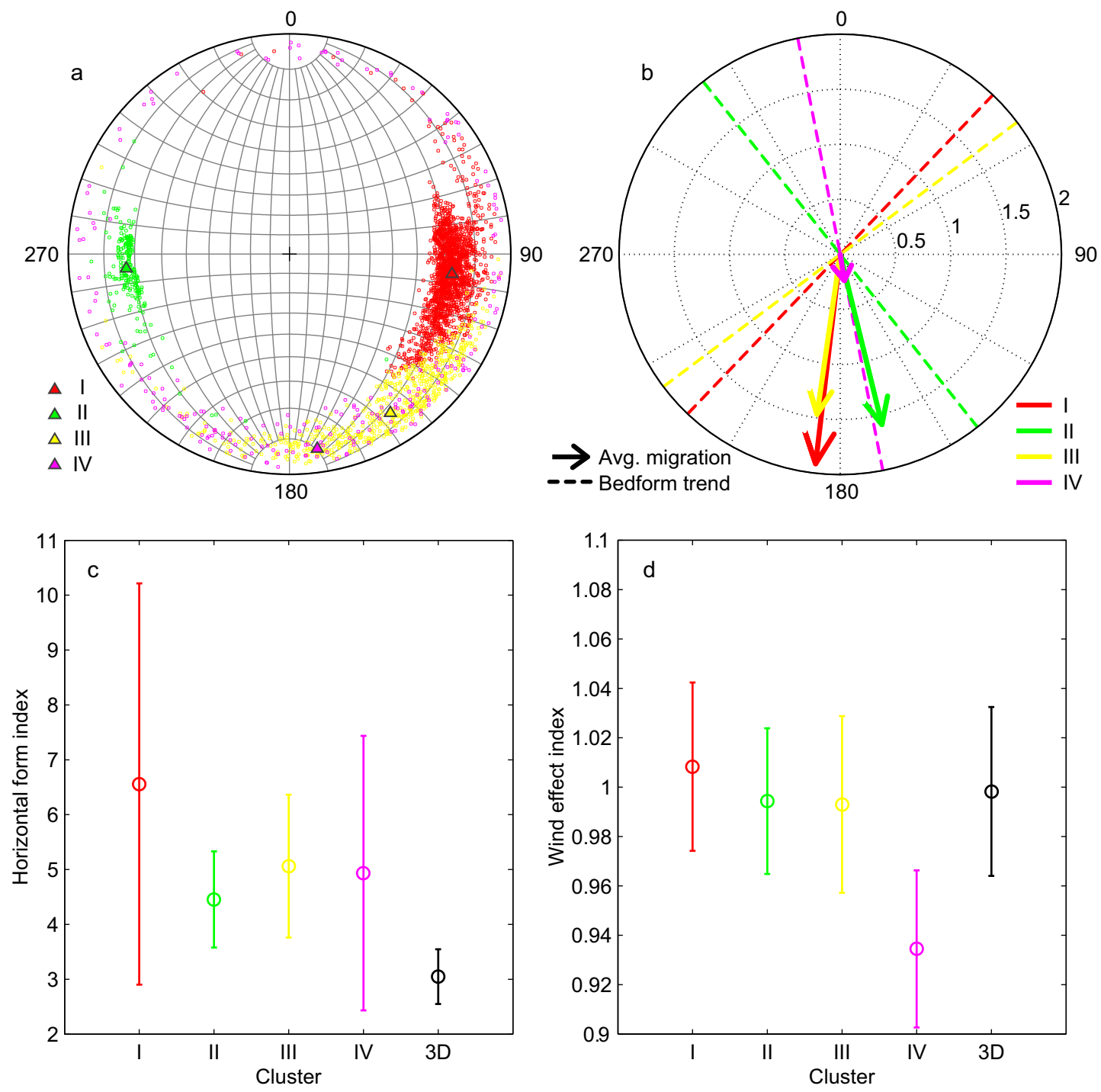

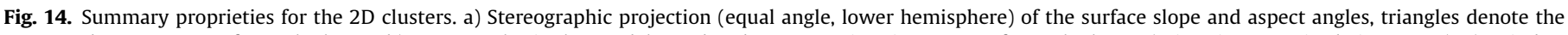

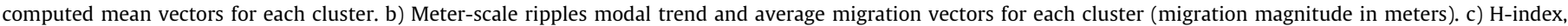
including the 3D large ripples for comparison. d) Wind effect index. See text for discussion.

spatial transitions are also recognizable on the spatial distribution of the 2D meter-scale ripples, indicating a multiscale coupling of topography, dunes and superimposed bedforms.

A striking common property of all the mapped meter-scale ripple patterns is that during the analyzed time interval, they have not migrated orthogonally to their trend. Dune slopes can generate relatively large deflections for clusters I and II, but the predicted slope effect (Howard, 1977) is not enough to completely justify the measured obliquities. The assumption that meter-scale ripples on Mars formed transversely to present winds may not be applicable in all cases, meaning that studies that used this assumption (Silvestro et al., 2011; Jackson et al., 2015; Liu and Zimbelman, 2015) need to be carefully revised. Another important implication is that quantifying sand fluxes from non-transverse migrating bedforms may require a different approach (e.g., Lucas et al., 2015), rather than simply measuring bedform displacements (Bridges et al., 2012).

A comparison of horizontal form indices of Martian meter-scale ripples and terrestrial ripples shows that they have very different planform geometries (Fig. 15). The presented results demonstrate that long and straight bedforms (two-dimensional or quasi-twodimensional) are rare on Herschel (less than $3 \%$ of the mapped area), in contrast with aeolian ripples on our planet. It is thus relevant to discuss which processes control bedform straightness. A review of this subject was given by Rubin (2012), where it is argued that all bedforms are initially three-dimensional, and would remain three-dimensional if along-crest coupling did not force crestlines to straighten. For terrestrial aeolian ripples, this coupling is caused by the lateral ejection of grains during the impact of saltating particles, but gravity driven along-crest transport on rippled slopes can also contribute for the straightening of the bedforms. The oblique nature of the bedforms (when their trend is not transverse to the direction of the flow) is another factor that also generates along-crest sediment transport, thus contributing for the elongation of the bedform crestlines.

For subaqueous unidirectional flows a progressive transition from two to three-dimensional bedform patterns was reported (Allen, 1968, 1969), representing an increase in the flow strength (Costello and Southard, 1981; Southard and Boguchwal, 1990). The same generic relation was reported for bedforms in the deep seafloor (Stow et al., 2009), with three-dimensional bedforms associated with higher flow velocities. However, the flume experiments conducted by Baas (1994) suggest that in underwater environments two-dimensional bedforms are never in equilibrium, always 


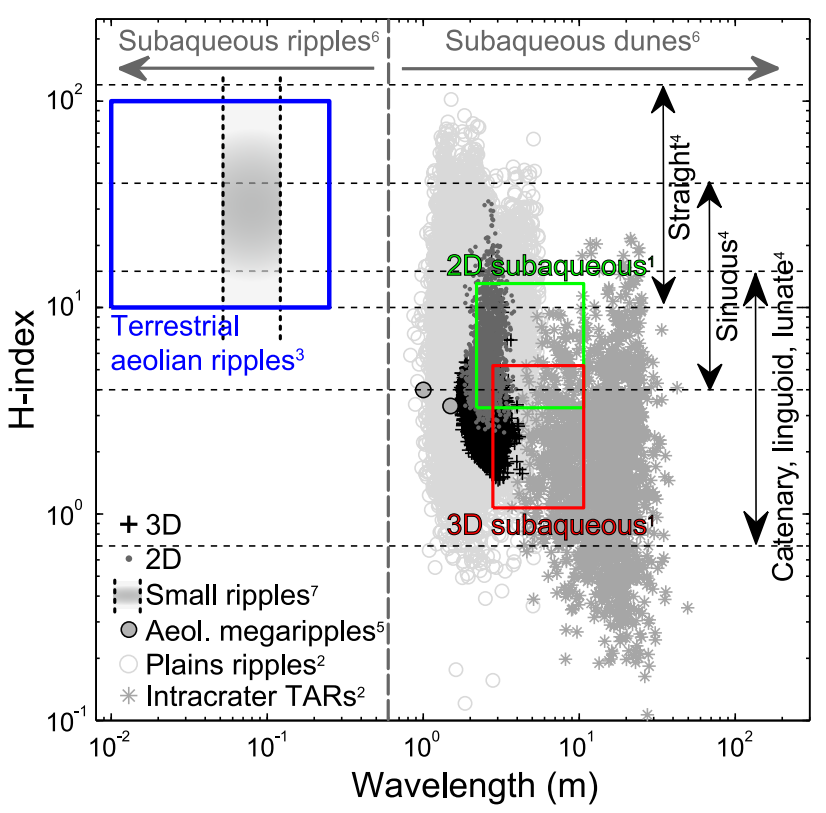

Fig. 15. Comparison of the horizontal form index (H-index) for the two segmented bedform classes (3D and 2D large Martian ripples), 2D and 3D subaqueous dunes ${ }^{1}$ (Elliott and Gardiner, 1981), intracrater TARs and plain ripples mapped in Meridiani Planum ${ }^{2}$ (Silvestro et al., 2015a), terrestrial aeolian ripples ${ }^{3}$ (Pye and Tsoar, 2009) and aeolian megaripples ${ }^{5}$ (average values from the Wadi Rum in Jordan and from Arava valley in Israel, by courtesy of Hezi Yizhaq). The H-index intervals associated with the several types of bedforms described by ${ }^{4}$ (Allen, 1968) and the wavelength threshold used to differentiate subaqueous ripples from subaqueous dunes ${ }^{6}$ (Ashley and Chairpers, 1990) are also shown. The small ripples with straight crest lines that cover the meter-scale bedforms are also depicted ${ }^{7}$ (Lapotre et al., 2016a), since length measurements were not reported we are assuming that they have $\mathrm{H}$-index values similar to terrestrial impact ripples.

transitioning to three-dimensional patterns regardless of flow velocities (flow velocity only controls the time necessary for this transition). Thus, a reliable simple association between the pattern dimensionality and the strength of the flow cannot be firmly established, as noted by Rubin (2012), who also pointed that this relation does not consider the importance of along-crest transport.

After evoking some key factors that can influence the dimensionality of bedform patterns, we try to explain and integrate the characteristics of the 2D large ripples observed on Herschel. The clustering of the 2D bedforms show that they appear associated with specific morphometric settings: cluster I and II with higher slopes and in the flanks of the barchans; cluster III with flatter areas on the top of the dunes (between the crest and the brink); and cluster IV in the wind sheltered leeside of the dunes.

Since 2D meter-scale bedforms (clusters I and II) appear to be associated with high slopes, their two-dimensionality may be easily explained by along-crest sediment transport induced by gravitydriven flows. High slopes are not associated with cluster III, but their trend is oblique to the prevailing $\mathrm{N}-\mathrm{S}$ sediment flux suggesting that in this case the oblique nature of the bedforms influences their dimensionality. In addition, the region located downwind of the crest (between the crest and the brink) is characterized by a deceleration of the flow (Wiggs et al., 1996), which in our case is well marked by a downwind transition from three to two-dimensional meter-scale ripples (Fig. 12d). As mentioned earlier, a well constrained relation between dimensionality and flow strength is not available, but this pattern transition suggests a change of flow and/or transport regime that deserves further investigation.

The interesting southward increase of the relative abundance of cluster III patterns (Fig. 13) can be explained by the increase of the distance between the crest and the brink of the dunes when moving south (with maximum distances attained for the dome dunes in the south of the region, after the B transition), which is well predicted by Wiggs' (1996) model of dune dynamics; a decrease of the distance between the brink and the crest occurs during dune evolution, until the formation of sharp-crested dunes. Field data supports this idea, showing that separated brinks exist preferentially on smaller dunes, while taller and larger barchans present coincident crests and brinks (Sauermann et al., 2000). More complex time variations of the distance between the brink and the crest were also reported from field observations (Elbelrhiti, 2015), suggesting the effect of seasonal wind variations. Therefore, the spatial distribution of this ripple cluster is related with the degree of maturity of the dunes (most likely reflecting the height of the dunes, compare the spatial distribution of cluster III with Fig. 10c) and/or different levels of wind scattering.

Secondary flows are generated inside the flow separation bubble that forms in the leeside of dunes (Frank and Kocurek, 1996; Ewing et al., 2010; Omidyeganeh et al., 2013), controlling the sediment transport in the interdune area. Cluster IV appears associated with this region of complex flows, which can converge and even present a reverse direction of flow near the surface (Sweet and Kocurek, 1990). The N-S trend of the bedforms in this cluster is then justified by the lateral flows that converge toward the central sections. This convergence is probably generating some degree of along-crest transport, thus contributing for the elongation of the large ripples and possible longitudinal defect migration (Silvestro et al., 2015b), in agreement with the longitudinal migration reported for this set of bedforms in this study. The very low average migration is also influenced by the local reversal of the flow inside the bubble (Fig. 5e), in a spatial context where upwind dune topography shelters the meter-scale ripples from the primary flow (as proven by the modeled wind effect).

This set of evidences show that meter-scale bedforms on Herschel are morphologically different and behave differently from terrestrial aeolian ripples. Contrary to terrestrial ripples, they only present a two-dimensional morphology in certain rare cases: in high slope areas and in areas where dune topography favors the occurrence of oblique meter-scale bedforms.

The combined analysis we performed is able to isolate the physical factors that justify the occurrence of the two-dimensional clusters, but the prevalence of three-dimensional patterns on Herschel ( $\sim 97 \%$ of the mapped patterns) remains to be explained. The same type of clustering applied to the 3D subset should help to segment and explain the pattern variations that are recognizable within this population, and that were overlooked in this work. Assuming that two-dimensionality only occurs due to the existence of factors that generate along-crest transport (Rubin, 2012), we speculate that at a meter scale these factors are absent or have a more reduced magnitude on Mars. Impact and lateral splash during saltation are factors that promote the straightening of impact ripples on Earth (Rubin, 2012). Hence, by excluding saltation as the most important factor for the formation of the large ripples, the wind-drag hypothesis proposed by Lapotre et al. (2016a) tacitly implies that 2D large ripples should be scarcer. All these arguments may help to justify the predominance of three-dimensional bedforms and the clear association of two-dimensional bedforms with gravity or obliquity effects. However, from our analysis we cannot exclude other possible causes, such as unsteady multidirectional winds which may for instance rework pre-existent bedforms forming more complex patterns.

Studying the ripple patterns on one area and try to generalize and extrapolate to an entire planet is obviously an oversimplification. The regional analysis of the dune patterns also shows that the assumption of a unidirectional wind regime on the mapped area is also questionable. Through this study we proved that a meticulous segmentation and compilation of the bedforms patterns is useful to explain the processes by which they emerge on Mars. Testing the 
proposed relations (between the patterns, morphometric and wind settings as well as genetic mechanisms) for the $2 \mathrm{D}$ subsets in other Martian dune fields is essential in order to understand the diversity of meter-scale bedforms that cover dark Martian dunes. The set of techniques applied in this study are able to extract and integrate automatically a large variety of data sources at different spatial scales allowing the systematic study of Martian aeolian bedforms.

\subsection{First observations from MSL at Gale}

During the preparation of this work, Curiosity rover has imaged for the first time (Bridges et al., 2016) an active dune field (Silvestro et al., 2013) located in Gale crater. The first collected images (Fig. 16) underpin the distinctive nature of Martian large ripples: they do not present two-dimensional crest forms (sinuous crests were reported) and they are covered by smaller centimeterscale ripples (Lapotre et al., 2016a).

The morphodynamic differences identified in this study indicate that terrestrial aeolian ripples are not the best analogues to meter-scale bedforms on Mars, suggesting that a different genetic mechanism (like the wind-drag hypothesis in Lapotre et al., 2016a) is necessary to explain their formation and evolution. Curiosity's preliminary observations together with the presented

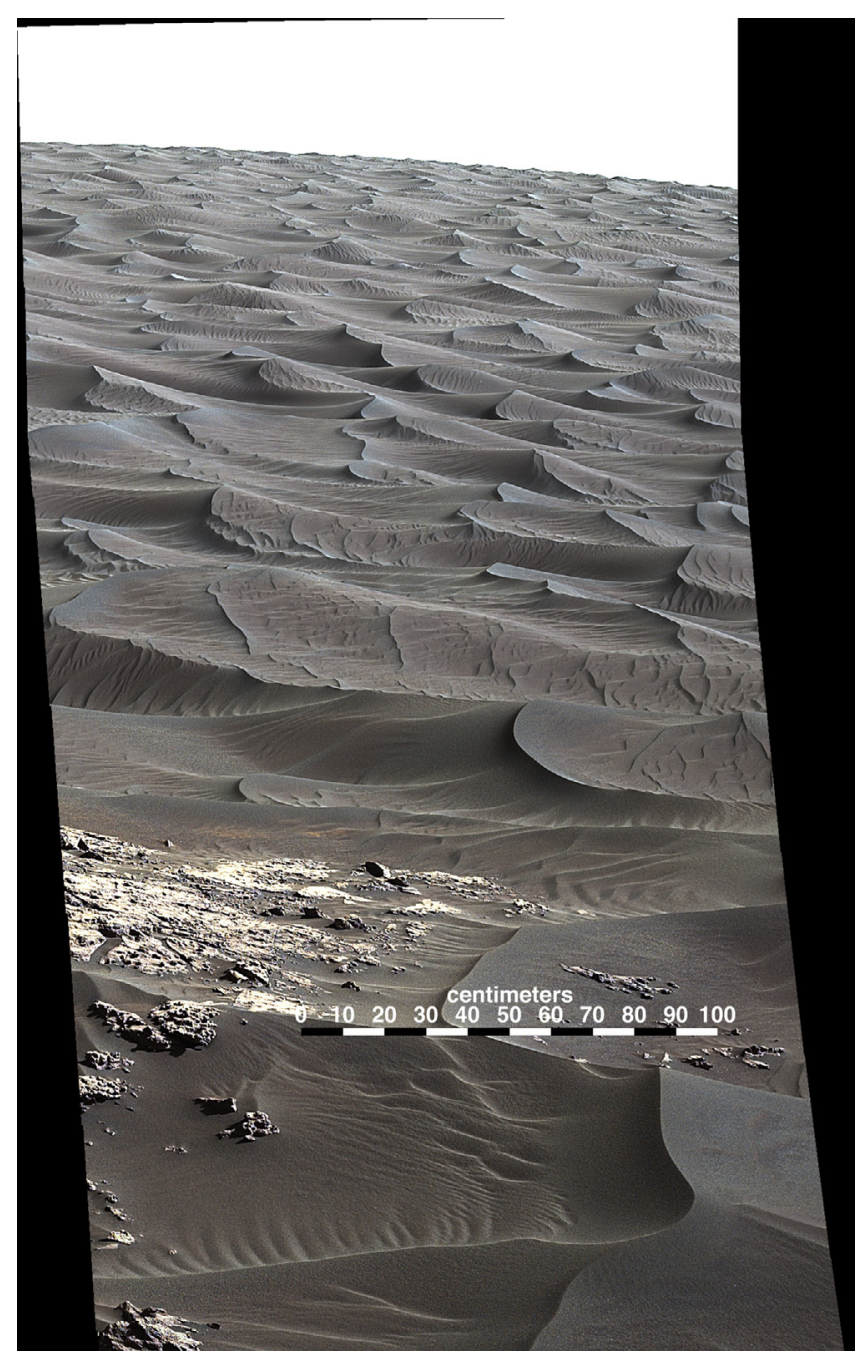

Fig. 16. Mastcam mosaic of bedforms in "High Dune" (sol 1176, Credit: NASA/JPLCaltech/MSSS). Asymmetric ripples with centimeter wavelengths are superimposed on the meter-scale bedforms, which present: stoss slopes and sharp-crested profiles, apparent concentration of coarser materials on the crests, longitudinal spurs and slipfaces. The high sinuosity of the patterns is evident. case on Herschel suggests a scenario where centimeter-scale bedforms are superimposed on meter-scale two or three-dimensional bedforms, a setting well known from subaqueous environments, where oblique bedforms like those described in this work also occur under the form of subaqueous dunes (Allen, 1968; Costello and Southard, 1981). As pointed by Lapotre et al. (2016a, 2016b), if aeolian processes on Mars are generating sedimentary figures similar in scale and form, and from our study, also presenting similar dynamic behavior to terrestrial subaqueous bedforms, planetary geologists must appeal to independent contextual clues to interpret the depositional environments of Martian sedimentary rocks.

\section{Conclusion}

In this paper we have for the first time presented a nested multiscale morphodynamic survey of dunes and large ripples on Mars. Using automatic mapping techniques, PCA and unsupervised clustering we demonstrated that long-wavelength topography exerts an important control on the spatial distribution of dunes at a regional scale. Such a topographic control particularly affects the density of dune elements which is inversely correlated with elevation and displays a transverse spatial upwind-downwind attenuation.

The same key aspects are recognizable at a more detailed scale of analysis. Using HiRISE images and DTM we have characterized the morphology and dynamics of the slipfaces, finding the same upwind-downwind transition this time expressed as a first-order decrease in slipface heights and migration rates. However, at this scale of analysis the influence of underlying $\mathrm{km}$-scale topography is also relevant, inducing second-order spatial variations on the dunes' morphodynamics. Moving to the ripples' scale, the same first and second-order variations are also identifiable in the spatial distribution of the segmented two-dimensional ripples. These evidences indicate an active multiscale coupling of topography, dunes and superimposed bedforms on Herschel under the influence of present atmospheric conditions.

Martian meter-scale ripples are morphologically distinct from terrestrial aeolian ripples, which present a higher degree of straightness. The segmentation of the ripple patterns proved that long and straight (two-dimensional) bedforms are rare on Herschel ( $\sim 3 \%$ of the mapped features). The clustering of the twodimensional set of ripples allowed the definition of four preferential settings where these bedforms occur. These specific morphometric settings can explain the exceptional two-dimensionality of the patterns. The identified factors that promote the elongation of the large ripples are: gravity transport on higher slopes, bedform obliquity and flow convergence on the leeward side of dunes.

Other very distinctive characteristic of Martian ripples is that over the analyzed time span they have not migrated orthogonally to their trend. Our analysis excludes dune slope as a factor that can entirely justify the measured deviations from a pure transverse migration of the large ripples. Our results show that the assumption that meter-scale bedforms on Mars formed transversely to present winds is not valid for all cases. Therefore we conclude that terrestrial aeolian ripples are not good analogues for Martian meter-scale bedforms, either in terms of morphology or dynamic evolution. The application of the approach followed in this work to other areas, and particularly to the segmentation of the more complex three-dimensional ripple patterns, can contribute to a better understanding of the distinct nature of Martian ripples.

\section{Acknowledgements}

We thank two anonymous reviewers and the journal editor for useful advice and comments. We thank Hezi Yizhaq for providing 
the field measurements and we acknowledge F. Ayoub (Caltech) for helping during the COSI-Corr displacement map production. This work was supported by FCT (Fundação para a Ciência e a Tecnologia) with the grant FRH/BPD/72371/2010 and the contracts UID/ Multi/00611/2013 and COMPETE2020/POCI-01-0145-FEDER-0069 22. S. Silvestro is supported by ASI through the ASI-CISAS agreement I/018/ 12/0: "DREAMS EDM Payload-ExoMars 2016".

\section{References}

Allen, J.R.L., 1968. Current Ripples; Their Relation to Patterns of Water and Sediment Motion. North-Holland Pub. Co., Amsterdam.

Allen, J.R.L., 1969. On the geometry of current ripples in relation to stability of fluid flow. Geogr. Ann. Ser. A, Phys. Geogr. 51 (1/2), 61-96.

Andreotti, B., Claudin, P., Pouliquen, O., 2006. Aeolian sand ripples: experimental study of fully developed states. Phys. Rev. Lett. 96 (2).

Ashley, G.M., Chairpers, S., 1990. Classification of large-scale subaqueous bedforms: a new look at an old problem-SEPM bedforms and bedding structures. SEPM J. Sediment. Res. 60.

Atwood-Stone, C., McEwen, A.S., 2013. Avalanche slope angles in low-gravity environments from active Martian sand dunes. Geophys. Res. Lett. 40 (12), 2929-2934.

Ayoub, F., Avouac, J.P., Newman, C.E., Richardson, M.I., Lucas, A., Leprince, S., Bridges, N.T., 2014. Threshold for sand mobility on Mars calibrated from seasonal variations of sand flux. Nat. Commun. 5.

Baas, J.H., 1994. A flume study on the development and equilibrium morphology of current ripples in very fine sand. Sedimentology 41 (2), 185-209.

Bagnold, R.A., 1941. The Physics of Blown Sand and Desert Dunes, Methuen, London.

Bohner, J., Antonic, O., 2009. Land-surface parameters specific to topo-climatology. Geomorphometry: Concepts, Software, Appl. 33, 195-226.

Bridges, N.T., Ayoub, F., Avouac, J.P., Leprince, S., Lucas, A., Mattson, S., 2012. Earthlike sand fluxes on Mars. Nature 485 (7398), 339-342.

Bridges, N., Geissler, P., Silvestro, S., Banks, M., 2013. Bedform migration on Mars: current results and future plans. Aeolian Res. 9, 133-151.

Bridges, N.T., Ehlmann, B.L., Ewing, R.C., Newman, C.E., Sullivan, R., Conrad, P.G., Cousin, A., Edgett, K.S., Fisk, M.R., Fraeman, A.A., Johnson, J.R., Lamb, M., Lapotre, M., Le Mouélic, S., Martinez, G.M., Meslin, P.Y., Pinet, P., Thompson, L.M., Van Beek, J., Vasavada, A.R., Wiens, R.C., 2016. Investigation of the Bagnold Dunes by the Curiosity Rover: Overview of Initial Results from the First Study of an Active Dune Field on Another Planet, Lunar and Planetary Science Conference, pp. 2298-2298.

Cardinale, M., Silvestro, S., Vaz, D.A., Michaels, T., Bourke, M.C., Komatsu, G., Marinangeli, L., 2016. Present-day aeolian activity in Herschel Crater, Mars. Icarus 265, 139-148.

Costello, W.R., Southard, J.B., 1981. Flume experiments on lower-flow-regime bed forms in coarse sand. SEPM J. Sediment. Res. 51 (3), 850-864.

du Pont, S.C., Narteau, C., Gao, X., 2014. Two modes for dune orientation. Geology 42 (9), 743-746.

Elbelrhiti, H., 2015. Field evidence of appearance and disappearance of the brink line on barchans. Aeolian Res. 18, 115-120.

Elliott, T., Gardiner, A.R., 1981. Ripple, Megaripple and Sandwave Bedforms in the Macrotidal Loughor Estuary, South Wales, U.K. In: Holocene Marine Sedimentation in the North Sea Basin. Blackwell Publishing Ltd., pp. 51-64.

Ewing, R.C., Peyret, A.-P.B., Kocurek, G., Bourke, M., 2010. Dune field pattern formation and recent transporting winds in the Olympia Undae Dune Field, north polar region of Mars. J. Geophys. Res. 115 (E8), E08005.

Ewing, R.C., McDonald, G.D., Hayes, A.G., 2015. Multi-spatial analysis of aeolian dune-field patterns. Geomorphology 240, 44-53.

Fenton, L.K., Hayward, R.K., 2010. Southern high latitude dune fields on Mars: morphology, aeolian inactivity, and climate change. Geomorphology 121 (1-2), 98-121.

Frank, A., Kocurek, G., 1996. Toward a model for airflow on the lee side of aeolian dunes. Sedimentology 43 (3), 451-458.

Geissler, P.E., Stantzos, N.W., Bridges, N.T., Bourke, M.C., Silvestro, S., Fenton, L.K., 2013. Shifting sands on Mars: insights from tropical intra-crater dunes. Earth Surf. Proc. Land. 38 (4), 407-412.

Howard, A.D., 1977. Effect of slope on the threshold of motion and its application to orientation of wind ripples. Geol. Soc. Am. Bull. 88, 853-856.

Hugenholtz, C.H., Levin, N., Barchyn, T.E., Baddock, M.C., 2012. Remote sensing and spatial analysis of aeolian sand dunes: a review and outlook. Earth Sci. Rev. 111 (3-4), 319-334.

Jackson, D.W.T., Bourke, M.C., Smyth, T.A.G., 2015. The dune effect on sandtransporting winds on Mars. Nat. Commun. 6.

Jerolmack, D.J., Ewing, R.C., Falcini, F., Martin, R.L., Masteller, C., Phillips, C., Reitz, M. D., Buynevich, I., 2012. Internal boundary layer model for the evolution of desert dune fields. Nat. Geosci. 5 (3), 206-209.

Lapotre, M.G.A., Ewing, R.C., Lamb, M.P., Fischer, W.W., Grotzinger, J.P., Rubin, D.M., Lewis, K.W., Ballard, M.J., Day, M., Gupta, S., Banham, S.G., Bridges, N.T., Des Marais, D.J., Fraeman, A.A., Grant, J.A., Herkenhoff, K.E., Ming, D.W., Mischna, M. A., Rice, M.S., Sumner, D.A., Vasavada, A.R., Yingst, R.A., 2016a. Large wind ripples on Mars: a record of atmospheric evolution. Science 353 (6294), 55-58.

Lapotre, M.G.A., Ewing, R.C., Lamb, M.P., Fischer, W.W., Lewis, K., Ballard, M., Day, M., Rubin, D., Grotzinger, J.P., 2016b. Orbital and in-situ observations in support of the existence of an unknown stable aeolian bedform regime on mars, 47th LPSC, p. \#1510.

Leprince, S., Barbot, S., Ayoub, F., Avouac, J.P., 2007. Automatic and precise orthorectification, coregistration, and subpixel correlation of satellite images, application to ground deformation measurements. IEEE Trans. Geosci. Remote Sens. 45 (6), 1529-1558.

Liu, Z.Y.C., Zimbelman, J.R., 2015. Recent near-surface wind directions inferred from mapping sand ripples on Martian dunes. Icarus 261, 169-181.

Lucas, A., Narteau, C., Rodriguez, S., Rozier, O., Callot, Y., Garcia, A., Courrech du Pont S., 2015. Sediment flux from the morphodynamics of elongating linear dunes. Geology 43 (11), 1027-1030.

McEwen, A.S., Eliason, E.M., Bergstrom, JW. Bridges, N.T., Hansen, C.J., Delamere, W. A., Grant, J.A., Gulick, V.C., Herkenhoff, K.E., Keszthelyi, L., Kirk, R.L., Mellon, M.T. Squyres, S.W., Thomas, N., Weitz, C.M., 2007. Mars reconnaissance orbiter's High Resolution Imaging Science Experiment (HiRISE). J. Geophys. Res.-Planets 112 (E5).

Nielson, J., Kocurek, G., 1987. Surface processes, deposits, and development of star dunes: Dumont dune field, California. Geol. Soc. Am. Bull. 99 (2), 177-186.

Omidyeganeh, M., Piomelli, U., Christensen, K.T., Best, J.L., 2013. Large eddy simulation of interacting barchan dunes in a steady, unidirectional flow. J. Geophys. Res.-Earth Surf. 118 (4), 2089-2104.

Parteli, E.J.R., Durán, O., Bourke, M.C., Tsoar, H., Pöschel, T., Herrmann, H., 2014 Origins of barchan dune asymmetry: insights from numerical simulations. Aeolian Res. 12, 121-133.

Pelletier, J.D., 2009. Controls on the height and spacing of eolian ripples and transverse dunes: a numerical modeling investigation. Geomorphology 105 (34), 322-333.

Pelletier, J.D., 2015. Controls on the large-scale spatial variations of dune field properties in the barchanoid portion of White Sands dune field, New Mexico. J. Geophys. Res.-Earth Surf. 120 (3), 453-473.

Pye, K., Tsoar, H., 2009. Aeolian bed forms. In: Pye, K., Tsoar, H. (Eds.), Aeolian Sand and Sand Dunes. Springer, Berlin, Heidelberg, pp. 175-253.

Rubin, D.M., 2012. A unifying model for planform straightness of ripples and dunes in air and water. Earth Sci. Rev. 113 (3-4), 176-185.

Sauermann, G., Rognon, P., Poliakov, A., Herrmann, H.J., 2000. The shape of the barchan dunes of Southern Morocco. Geomorphology 36 (1-2), 47-62.

Sharp, R.P., 1963. Wind ripples. J. Geol. 71 (5), 617-636.

Silvestro, S., Fenton, L.K., Vaz, D.A., Bridges, N.T., Ori, G.G., 2010. Ripple migration and dune activity on Mars: evidence for dynamic wind processes. Geophys. Res. Lett. 37 (20), L20203.

Silvestro, S., Vaz, D.A., Fenton, L.K., Geissler, P.E., 2011. Active aeolian processes on Mars: a regional study in Arabia and Meridiani Terrae. Geophys. Res. Lett. 38 (20), L20201.

Silvestro, S., Vaz, D.A., Ewing, R.C., Rossi, A.P., Fenton, L.K., Michaels, T.I., Flahaut, J, Geissler, P.E., 2013. Pervasive aeolian activity along rover Curiosity's traverse in Gale Crater, Mars. Geology 41 (4), 483-486.

Silvestro, S., Vaz, D.A., Di Achille, G., Popa, I.C., Esposito, F., 2015a. Evidence for different episodes of aeolian construction and a new type of wind streak in the 2016 ExoMars landing ellipse in Meridiani Planum, Mars. J. Geophys. Res. Planets 120 (4), 760-774.

Silvestro, S., Vaz, D.A., Popa, C., Esposito, F., 2015b. Longitudinal Aeolian Depositional Features on Mars?, Fourth Annual International Planetary Dunes Workshop, Boise, Idaho.

Southard, J.B., Boguchwal, L.A., 1990. Bed configuration in steady unidirectional water flows; Part 2, Synthesis of flume data. J. Sediment. Res. 60 (5), 658-679.

Stow, D.A.V., Hernandez-Molina, F.J., Llave, E., Sayago-Gil, M., Diaz del Rio, V. Branson, A., 2009. Bedform-velocity matrix: the estimation of bottom current velocity from bedform observations. Geology 37 (4), 327-330.

Sweet, M.L., Kocurek, G., 1990. An empirical model of aeolian dune lee-face airflow Sedimentology 37 (6), 1023-1038.

Tso, B., Mather, P.M., 2001. Classification Methods for Remotely Sensed Data. Taylor \& Francis, New York.

Vaz, D.A., 2011. Analysis of a Thaumasia Planum rift through automatic mapping and strain characterization of normal faults. Planet. Space Sci. 59 (11-12), 1210-1221.

Vaz, D.A., Silvestro, S., 2014. Mapping and characterization of small-scale aeolian structures on Mars: An example from the MSL landing site in Gale Crater. Icarus 230, 151-161.

Vaz, D.A., Spagnuolo, M.G., Silvestro, S., 2014. Morphometric and geometric characterization of normal faults on Mars. Earth Planet. Sci. Lett. 401, 83-94.

Vaz, D.A., Sarmento, P.T.K., Barata, M.T., Fenton, L.K., Michaels, T.I., 2015a. Objectbased dune analysis: automated dune mapping and pattern characterization for Ganges Chasma and Gale crater, Mars. Geomorphology 250, 128-139.

Vaz, D.A., Sarmento, P.T.K., Silvestro, S., Cardinale, M., 2015b. Ripple Pattern Analysis in Herschel Crater, Fourth Annual International Planetary Dunes Workshop, Boise, Idaho.

Wiggs, G.F.S., Livingstone, I., Warren, A., 1996. The role of streamline curvature in sand dune dynamics: evidence from field and wind tunnel measurements. Geomorphology 17 (1-3), 29-46.

Winstral, A., Elder, K., Davis, R.E., 2002. Spatial snow modeling of wind-redistributed snow using terrain-based parameters. J. Hydrometeorol. 3 (5), 524-538.

Zimbelman, J.R., Johnson, M.B., 2015. Surface slope effects for ripple orientations on sand dunes in Lopez Crater, Terra Tyrrhena region, Mars, LPSC 2015 p. \#1478. 